\title{
Phosphatidylinositol synthase is required for lens structural integrity and photoreceptor cell survival in the zebrafish eye
}

\author{
Taylor R. Murphy ${ }^{1}$, Thomas S. Vihtelic ${ }^{1}$, Kristina E. Ile ${ }^{2}$, Corey T. Watson ${ }^{3}$, Gregory B. \\ Willer $^{3}$, Ronald G. Gregg ${ }^{3}$, Vytas A. Bankaitis ${ }^{2}$, and David R. Hyde ${ }^{1, *}$
}

Taylor R. Murphy: tmurphy4@nd.edu; Thomas S. Vihtelic: Thomas.Vihtelic@mpiresearch.com; Kristina E. Ile: kristina.ile@tuebingen.mpg.de; Corey T. Watson: ctwatson@sfu.ca; Gregory B.Willer: gregwiller@hotmail.com; Ronald G. Gregg: ron.gregg@louisville.edu; Vytas A. Bankaitis: vytas@med.unc.edu; David R. Hyde: dhyde@nd.edu

${ }^{1}$ Department of Biological Sciences and Center for Zebrafish Research, University of Notre Dame, Notre Dame, IN 46556

2Department of Cell and Developmental Biology, University of North Carolina School of Medicine, Chapel Hill, NC 27599

${ }^{3}$ Mutant Zebrafish Mapping Facility, University of Louisville, Louisville, KY 40202

\section{Abstract}

The zebrafish lens opaque (lop) mutant was previously isolated in a genetic screen and shown to lack rod and cone photoreceptors and exhibit lens opacity, or cataract, at 7 days post-fertilization (dpf). In this manuscript, we provide four different lines of evidence demonstrating that the lop phenotype results from a defect in the cdipt (phosphatidylinositol (PI) synthase; CDPdiacylglycerol--inositol 3-phosphatidyltransferase) gene. First, DNA sequence analysis revealed that the lop mutant contained a missense mutation in the lop open reading frame, which yields a nonconservative amino acid substitution (Ser-111-Cys) within the PI synthase catalytic domain. Second, morpholino-mediated knockdown of the cdipt-encoded PI synthase protein phenocopied the $c_{\text {dipt }}{ }^{l o p / l o p}$ mutant, with abnormal lens epithelial and secondary fiber cell morphologies and reduced numbers of photoreceptors. Third, microinjection of in vitro transcribed, wild-type cdipt mRNA into 1-4 cell stage $c$ dipt $t^{l o p / l o p}$ embryos significantly reduced the percentage of larvae displaying lens opacity at $7 \mathrm{dpf}$. Fourth, a cdipt retroviral-insertion allele, cdipt $^{h i 559}$, exhibited similar lens and retinal abnormalities and failed to complement the $c d i p t^{l o p}$ mutant phenotype.

To determine the initial cellular defects associated with the cdipt mutant, we examined homozygous $c$ dipt ${ }^{h i 559 / h i 559}$ mutants prior to gross lens opacification at 6 dpf. The $c d i p t^{h i 559 / h i 559}$ mutants first exhibited photoreceptor layer disruption and photoreceptor cell death at 3 and $4 \mathrm{dpf}$, respectively, followed by lens dismorphogenesis by $5 \mathrm{dpf}$. RT-PCR revealed that the cdipt gene is maternally expressed and continues to be transcribed throughout development and into adulthood, in a wide variety of tissues. Using an anti-zebrafish PI synthase polyclonal antiserum, we localized the protein throughout the developing eye, including the photoreceptor layer and lens cortical secondary fiber cells. As expected, the polyclonal antiserum revealed that the PI synthase protein was reduced in amount in both the $c$ dipt ${ }^{l o p / l o p}$ and $c d i p t^{h i 559 / h i 559}$ mutants. Furthermore, we used a heterologous yeast phenotypic complementation assay to confirm that the wild-type zebrafish

\section{(C) 2011 Elsevier Ltd. All rights reserved.}

* Correspondence sent to: David R. Hyde, Ph.D., Department of Biological Sciences, Galvin Life Science Building, University of Notre Dame, Notre Dame, Indiana, 46556, dhyde@nd.edu, Phone: 574-631-8054, Fax: 574-631-7413.

Publisher's Disclaimer: This is a PDF file of an unedited manuscript that has been accepted for publication. As a service to our customers we are providing this early version of the manuscript. The manuscript will undergo copyediting, typesetting, and review of the resulting proof before it is published in its final citable form. Please note that during the production process errors may be discovered which could affect the content, and all legal disclaimers that apply to the journal pertain. 
cdipt allele encodes functional PI synthase activity. Taken together, the $c$ dipt-encoded PI synthase is required for survival of photoreceptor cells and lens epithelial and secondary cortical fiber cells. These zebrafish cdipt alleles represent excellent in vivo genetic tools to study the role of phosphatidylinositol and its phosphorylated derivatives in lens and photoreceptor development and maintenance.

\section{Keywords}

Phosphatidylinositol synthase; photoreceptor; lens epithelial cell; lens fiber cell; cell death; cataract

\section{Introuction}

Zebrafish is an ideal model system to study the vertebrate lens and retina because of their rapid development and highly conserved structural organization with the mammalian eye (Easter and Nicola 1996; Glass and Dahm 2004; Dahm et al. 2007; Vihtelic 2008). Between 16-20 hpf (hours post fertilization), the zebrafish lens begins to form by the thickening of overlying surface ectoderm to form the solid lens placode (Schmitt and Dowling 1994; Dahm et al. 2007; Vihtelic 2008; Greiling and Clark 2009). Between 22-24 hpf, this placode delaminates to yield the lens mass (Greiling and Clark 2009), which is analogous to the lens vesicle. By $30 \mathrm{hpf}$, cuboidal-shaped lens epithelial cells are present on the anterior surface of the developing lens, primary fiber cells surround the core of the lens nucleus, and secondary fiber cells are elongating and moving posteriorly (Greiling and Clark 2009), while the inner layer of the adjacent optic cup begins to generate the neural retina (Hu 1999; Easter and Malicki 2002; Dahm et al. 2007; Vihtelic 2008). At $52 \mathrm{hpf}$, newly differentiating rod and cone photoreceptors begin expressing opsin genes (Nawrocki et al. 1985; Raymond et al. 1995; Schmitt and Dowling 1996; Schmitt and Dowling 1999; Vihtelic et al. 1999; Soules and Link 2005; Dahm et al. 2007). By $72 \mathrm{hpf}$, the lens is spherical and the visual system is functional based on behavioral tests (Soules and Link 2005; Easter and Nicola 1996; Bilotta 2000; Li 2001; Neuhauss 2003; Greiling and Clark 2009).

A variety of zebrafish mutants display abnormal eye development, some of which model human ocular diseases (Barut and Zon 2000; Shin and Fishman 2002; Fadool and Dowling 2008). For example, mutants that perturb lens formation include laminin alpha 1 (lamal ${ }^{\text {arl }}$ ) and disrupted lens (dsl) (Vihtelic et al. 2001; Vihtelic and Hyde 2002; Semina et al. 2006; Zinkevich et al. 2006). The lamal ${ }^{\text {arl }}$ mutant exhibits defects in the lens epithelial cell population at $5 \mathrm{dpf}$, without significantly affecting the organization and survival of retinal neurons (Vihtelic et al. 2001; Semina et al. 2006). Interestingly, mutations in the LAMB2 (laminin beta 2) protein, which directly interacts with LAMA1, cause cataracts, glaucoma, and microphthalmia in humans (Colognato and Yurchenco 2000; Semina et al. 2006; Zinkevich et al. 2006; Bredrup et al. 2008).

In the same chemical mutagenesis screen that identified the lama ${ }^{\text {arl }}$ allele and other zebrafish mutants with abnormal eye morphologies (Vihtelic and Hyde 2002), we isolated the lens opaque (lop) mutant that exhibited an opaque lens beginning at $7 \mathrm{dpf}$ (Vihtelic et al. 2005). Immunostaining revealed that maturation of the lop lens secondary fiber cells was disrupted. The lop mutant also exhibited increased numbers of proliferating cells in both the lens and anterior chamber relative to controls, which suggested abnormal proliferation within the distal lens epithelial cell population. Surprisingly, the lop central retina lacked both rod and cone photoreceptors at $7 \mathrm{dpf}$, while the wild-type zebrafish retina possessed a full complement of retinal neurons, including rods and cones (Johns 1981; Easter and Nicola 1996; Schmitt and Dowling 1996; Schmitt and Dowling 1999; Vihtelic et al. 2005). Lens 
transplant experiments at $31 \mathrm{hpf}$ demonstrated that both the lens and retinal phenotypes were lens-autonomous, suggesting that the mutant lens disrupted retinal development (Vihtelic et al. 2005). The underlying molecular defects in the lop mutant leading to these phenotypes, however, were unknown.

This study reveals that the lop mutation is a missense mutation in the cdipt (CDPdiacylglycerol:myo-inositol 3-phosphatidyltransferase) gene encoding the PI synthase enzyme. Using the previously identified retroviral-insertion allele $c$ dipt ${ }^{h i 559}$ (Amsterdam et al. 2004), we PCR-genotyped $c d i p t^{h i 559 / h i 559}$ homozygotes to determine that the earliest ocular phenotype occurred within the photoreceptor layer at $3 \mathrm{dpf}$, followed by lens dismorphogenesis beginning at $5 \mathrm{dpf}$. The cdipt gene, which is initially expressed maternally, continues to be expressed in a variety of adult tissues. A polyclonal antisera specific to zebrafish PI synthase localized the protein throughout the developing eye and brain. To our knowledge, these zebrafish $c$ dipt alleles are the first vertebrate PI synthase mutants to be identified and represent an excellent in vivo genetic model to elucidate the function of PI synthase in the maintenance of lens transparency and photoreceptor survival.

\section{Materials and Methods}

\subsection{Zebrafish maintenance}

Wild-type, $c$ dipt $t^{l o p}$ mutant (Vihtelic et al. 2005) and $c d i p t^{h i 559}$ mutant (Amsterdam et al. 2004) zebrafish stocks were maintained at the Center for Zebrafish Research at the University of Notre Dame Freimann Life Science Center using standard husbandry protocols (Westerfield 2000). The fish were raised in a daily light cycle of 14 hours light/10 hours dark. Embryos from wild-type mass-matings and mutant pair-matings were reared at $28.5^{\circ} \mathrm{C}$ and staged according to hours post fertilization (hpf) or days post fertilization (dpf) using morphological criteria (Kimmel et al. 1995). All experimental procedures were conducted in agreement with the Animal Care and Use Committee at the University of Notre Dame and the principles of the ARVO statement on the use of animals for vision research.

\subsection{Complementation analysis}

Adult heterozygous $c d i p t^{h i 559 /+}$ and $c$ dipt ${ }^{l o p /+}$ mutants were crossed, and the resulting larvae were stereoscopically examined at $7 \mathrm{dpf}$ for the lop mutant phenotype. The transheterozygous mutants, as well as age-matched wild-type controls, were processed for histological analysis. A minimum of four fish of each genotype $(n=8$ eyes) were examined by histology.

\subsection{Histology}

Wild-type and mutant larvae were fixed in $2 \%$ formaldehyde $/ 2.5 \%$ glutaraldehyde $/ 0.1 \mathrm{M}$ cacodylate ( $\mathrm{pH} 7.4$ ) overnight at $4^{\circ} \mathrm{C}$. Larvae were washed in $100 \mathrm{mM}$ cacodylate for 30 minutes, rinsed with water, and dehydrated through a series of ethanol washes before being infiltrated with Polybed 812 (Polysciences; Warrington, PA) as previously described (Vihtelic et al. 2001; Shi et al. 2005; Harding et al. 2008). Three micron serial sections were taken using a glass knife on a Sorvall JB4 microtome and stained with $0.5 \%$ methylene blue/ $0.5 \%$ azure II. A minimum of four fish of each genotype ( $\mathrm{n}=8$ eyes) were examined by histology.

\subsection{Positional cloning}

Bulked segregant analysis mapped the lop mutation to chromosome 3 between the simple sequence-length polymorphic markers Z59420 and Z59380 (Knapik et al. 1998; Shimoda et al. 1999; Willer et al. 2005). High resolution linkage mapping using single nucleotide polymorphisms refined the genomic region to $200 \mathrm{~Kb}$ within BAC DKEY-183N6. 
Candidate genes within this critical interval were evaluated by cDNA sequencing (Willer et al. 2005).

\subsection{Yeast tetrad analysis}

A single genomic copy of the essential yeast phosphatidylinositol synthase (PIS1) gene was replaced with a KanMx (G418) cassette in the diploid strain CTYD1 (Mata/a ura3-52/ ura3-52 lys2-801/lys2-801 his34-200/his34-200 ade2-101/ADE2 TRP1/trp1A SEC14/ sec $14-1^{\text {ts }}$ ) to generate a $P I S 1^{+} /$pis $1 \Delta$ heterozygous diploid strain (Bankaitis et al. 1989). The replacement cassette was generated by PCR-amplification of KanMx with primers corresponding to flanking regions of PIS1 (Forward: 5'-

GTAATGTAAATAAGAGGGAAAGTGTGATAGTACAAGAGATCTGTTTAGCTTGCC TCGTC-3'; Reverse: 5'-

CAATTAAAAGGAGAAAAAAAGTAAGAAACTCATCCTAGTTTTCGACACTGGAT GGCGGC-3'). The gel-purified PCR-product was transformed into the CTYD1 strain using standard lithium acetate methods (Ito et al. 1983; Rothstein 1983; Gietz et al. 1995). After a four-hour recovery in non-selective media, the yeast transformants were plated onto yeastpeptone-dextrose (YPD) solid media supplemented with $200 \mu \mathrm{g} / \mathrm{ml} \mathrm{G418.} \mathrm{Large} \mathrm{G418}{ }^{\mathrm{r}}$ colonies were picked and genomic DNA was prepped to confirm the desired replacement events by PCR amplification with a forward primer that hybridized to a sequence in the PISI 5' UTR, located outside of the replacement cassette, and a reverse primer within the KanMX gene.

To generate zebrafish cdipt expression plasmids, the wild-type zebrafish cdipt cDNA (accession number BC155271) was subcloned into the XhoI and SacII sites of the yeast episomal shuttle vector pDR195 (Rentsch et al. 1995). This plasmid, along with the pDR195 vector control, carry the selectable URA3 marker and were transformed into the CTYD1 PIS1/pis14::KanMx heterozygous strain using the lithium acetate method. The desired transformants were recovered by selection for uracil prototrophy.

CTYD1 PIS1/pis14::KanMx heterozygous diploids were induced to sporulate by incubation in $2 \%$ potassium acetate supplemented with amino acids at $25^{\circ} \mathrm{C}$ for five days. Four-spore tetrads were visually identified under a light microscope, individually dissected by micromanipulation, and individual spores dispersed into ordered arrays onto solid YPD medium by standard methods. The individual meiotic progeny derived from each four-spore germinated and grew into colonies at $25^{\circ} \mathrm{C}$ for four days. For genotyping, these meiotic progeny were replica plated onto minimal media dropout plates lacking uracil, histidine, adenine, or tryptophan, and onto YPD plates either supplemented with G418 or not. In addition, genomic DNA was extracted from individual colonies and PCR amplified to further confirm the PIS1 and pis1A :KanMx genotypes using three primer sets: the wild-type PIS1 allele primers (Forward: 5'-GCCCCTCCTATTGTTTTTTCCG-3'; Reverse: 5'GCCATGGTTCCGTCTAGCGCATCC-3'), the PISl 5' UTR (Forward: 5'GCCCCTCCTATTGTTTTTTCCG-3') and KanMX cassette (Reverse: 5'CTCTACAGGGGCGCGGCGTGGGG-3') primers used to diagnose the pis1 $\because: K a n M x$ allele, and the zebrafish cdipt gene primers (Forward: 5'CCGAAGAAAATATATTCCTGTTCG-3'; Reverse: 5'GGAACAGAAAAGTGTAGGACGGG-3').

\subsection{Morpholino-mediated protein knockdown and lop phenocopy}

Two lissamine-tagged anti-sense morpholino oligomers (Gene Tools; Philomath, OR) were designed to target the $c$ dipt gene. The translation-blocking morpholino (MO1, 5'ATGATGCCGAGAGTTTCTTTCTTTG-3') anneals to the 5' untranslated region and the beginning of the cdipt open reading frame. The splice-inhibiting morpholino (MO2, 5'- 
CGAGCTGCAAAAGACCTTGATTGAG-3') anneals to the exon 2-intron 2 junction of the cdipt pre-mRNA. A control morpholino (5-mis MO2) was used that contained 5 mismatched bases relative to the experimental MO2 morpholino (5'-

CGAcCTcCAAAAcACgTTcATTGAG-3'). Morpholinos were resuspended in nuclease-free water to $0.5 \mathrm{mM}$ working concentrations and microinjected into 1-4 cell stage embryos as previously described (Thummel et al. 2004; Wei et al. 2004; Shi et al. 2005). Both MO1 and $\mathrm{MO}$ 2, but not the 5-mis MO2, produced phenotypes similar to the $c$ dipt ${ }^{l o p}$ lens and retinal phenotypes.

RT-PCR evaluated the efficacy of $c$ dipt pre-mRNA splice inhibition in the MO2 morphants (Draper et al. 2001). A forward primer (5'-CTCTCGGCATCATGACCGAAG-3') and a reverse primer (5'-GTGTAGGACGGGTACAGCAGTGCC-3') that anneals to sequences within exons 1 and 3, respectively, were used to amplify cDNA pools from wild-type and morphant embryos at $3 \mathrm{dpf}$.

\section{7. cdipt mRNA microinjections}

PCR primers (Forward: 5'-CTCGAGGAAGACAATTCAGGGAGCTCCG-3'; Reverse: 5'AGATCTCAGCTTCATCTCGCTGTCAGGA-3') were designed with internal XhoI and $B g l I I$ restriction sites to facilitate subcloning the zebrafish cdipt open reading frame into the pXT7 vector (courtesy of Dr. Len Zon) containing the 5' and 3' UTR of the h-globin gene. Recombinant plasmids were sequenced to verify their identities (Sequetech; Mountain View, $\mathrm{CA})$ and then linearized and in vitro transcribed according to the manufacturer's protocol (mMessage mMachine, Ambion; Austin, TX). The in vitro synthesized and capped mRNA was quantified using a NanoDrop spectrophotometer (Thermo Scientific; Wilmington, DE). Embryos from a heterozygous $c$ dipt $t^{l o p /+}$ pairmating were microinjected at the 1-4 cell stage with either $50 \mathrm{ng} / \mu \mathrm{l}$ in vitro synthesized cdipt mRNA or nuclease-free water as previously described (Thummel et al. 2004; Wei et al. 2004; Shi et al. 2005). Embryos were stereoscopically analyzed at $7 \mathrm{dpf}$ for the lop lens phenotype. A minimum of 44 fish of each type (uninjected, water-injected mRNA-injected) were examined.

\subsection{PCR genotyping}

Adult $c$ dipt ${ }^{h i 559 /+}$ heterozygous mutants were genotyped by PCR amplification. To extract genomic DNA, clipped fins were homogenized in $0.4 \mathrm{M} \mathrm{NaCl} / 10 \mathrm{mM}$ Tris- $\mathrm{HCl}(\mathrm{pH}$ 8.0)/2 mM EDTA (pH 8.0) before adding $40 \mu \mathrm{L}$ of $20 \%$ SDS and $160 \mu \mathrm{g}$ of Proteinase K (New England Biolabs, Inc.; Ipswich, MA). Samples were incubated with inversion at $65^{\circ} \mathrm{C}$ for 3 hours and then microcentrifuged for 30 minutes. Supernatant was transferred to a new tube and microcentrifuged for 5 minutes. DNA was precipitated from the supernatant with $100 \%$ ethanol at $-80^{\circ} \mathrm{C}$ for 1 hour, followed by microcentrifugation for 20 minutes. The DNA pellet was washed with $70 \%$ ethanol, microcentrifuged for 5 minutes, vacuum-dried for 15 minutes and resuspended in nuclease-free water. The resulting genomic DNA samples were PCR amplified using a primer pair (Forward primer MSL4, 5'-

GCTAGCTTGCCAAACCTACAGGT-3'; Reverse primer 559 TJU, 5'GTCAAACCAACCGATGTCACAATC-3') for 38 cycles at $94^{\circ} \mathrm{C}$ for 30 seconds, $60^{\circ} \mathrm{C}$ for 30 seconds, $68^{\circ} \mathrm{C}$ for 1 minute and a final termination step at $68^{\circ} \mathrm{C}$ for 10 minutes. The cdipt $t^{h i 559}$ allele produced a 191 base pair product corresponding to a small region of the retroviral insertion within the first intron of the cdipt gene.

To distinguish $c$ dipt $t^{h i 559 /+}$ heterozygotes from $c$ dipt ${ }^{h i 559 / h i 559}$ homozygotes, individual larval bodies were removed posterior of the head for genotyping at 3, 4, 5, or $6 \mathrm{dpf}$, while the corresponding heads were processed for either histology or immunohistochemistry. The MSL4 and 559 TJU primers amplified a 191 bp product from the $c d i p t^{h i 559}$ mutant allele. A second forward primer (pp2: 5'-CTGCAGTGCGCGGTGCGAG-3'), in combination with 
the $559 \mathrm{TJU}$ reverse primer, amplified a 330 bp product from the wild-type allele that was present in the $c$ dipt ${ }^{h i 559 /+}$ heterozygotes but not in the $c$ dipt ${ }^{h i 559 / h i 559}$ homozygotes.

\subsection{Immunohistochemistry}

Larvae were fixed in 9:1 ethanolic formaldehyde at $4^{\circ} \mathrm{C}$ overnight (Vihtelic et al. 2001; Vihtelic et al. 2005; Harding et al. 2008). Tissues were rehydrated through an ethanol series and washed in 5\% sucrose/PBS before embedding in 1.5\% agarose/5\% PBS and cryoprotecting in $30 \%$ sucrose/PBS overnight at $4^{\circ} \mathrm{C}$. The embedded fish were infiltrated with tissue freezing medium (TFM, Triangle Biomedical Sciences; Durham, NC) and 30\% sucrose/PBS (1:1) for 4 hours at room temperature, followed by a second infiltration with TFM and 30\% sucrose/PBS (2:1) at room temperature for 4 hours. Finally, the embedded tissues were incubated in $100 \%$ TFM at $4^{\circ} \mathrm{C}$ overnight. $12 \mu \mathrm{m}$ thick tissue sections were taken and dried on SuperFrost Plus slides (Fischer Scientific; Pittsburgh, PA) at $42^{\circ} \mathrm{C}$ for 2 hours before storing at $-80^{\circ} \mathrm{C}$. Upon use, tissue sections were rehydrated in PBS for 20 minutes, blocked in PBS/2\% normal goat serum/1\% DMSO/0.3\% Triton X-100 for 1 hour at room temperature, and incubated overnight in primary antibody diluted in blocking buffer (anti-PI synthase diluted 1:250, anti- $\alpha$ A crystallin diluted 1:500). The sections were washed in PBS/0.5\% Tween-20 ( $3 \times 10$ minutes), incubated for 1 hour with a goat anti-rabbit IgG AF594-conjugated secondary antibody ( $2 \mathrm{mg} / \mathrm{ml}$, Molecular Probes; Eugene, OR) diluted 1:500 in blocking buffer, and washed again in PBS/0.5\% Tween-20 ( $3 \times 10$ minutes) before a final PBS rinse for 5 minutes. Cover slips were mounted with ProLong Gold (Invitrogen, Carlsbad, CA) and imaged using a Leica TCS SP2 laser scanning confocal microscope. A minimum of six fish of each age and genotype $(n=12$ eyes) were examined with each antibody.

The Apoptosis Detection Kit (R\&D Systems, Minneapolis, MN) was used to assay cell death in wild-type and $c$ dipt $^{\text {hi }} 559 / / h i 559$ frozen tissue sections at 3, 4 or $5 \mathrm{dpf}$ as previously described (Vihtelic et al. 2006). Larvae were fixed overnight in ethanolic formaldehyde (9:1) and processed for cryosectioning as described above. After rehydration in PBS, Neuropore (R\&D Systems) was used to permeablize tissues and TUNEL-labeled nicked nucleic acid was detected using a streptavidin-fluorescein conjugate. A minimum of six fish of each age and genotype ( $\mathrm{n}=12$ eyes) were examined.

\subsection{Reverse transcriptase-polymerase chain reaction}

Reverse transcriptase-polymerase chain reaction (RT-PCR) amplification was performed essentially as described previously (Shi et al. 2006). RNA was isolated from 3, 12, 18, 24, 36, 48 hpf embryos (RNA-aqueous-4PCR, Ambion; Austin, TX) and cDNA was synthesized (First Strand cDNA Synthesis, Invitrogen). RNA was also isolated and cDNA made from adult brain, caudal fin, a mixture of internal organs, the ocular lens, anterior eye segments without the lens, posterior eye segments without the retina, and the retina. The cDNA pools were amplified with primers annealing within the third exon and the $3^{\prime}$ UTR of the cdipt gene (Forward: 5'- GGGAGCCACTAGTCACAAGGCC-3'; Reverse: 5'-

GGACGAAAATAATGCCAAAGCC-3') for either 38 (embryonic and larval tissues) or 35 (adult tissues) cycles at $94^{\circ} \mathrm{C}$ for 30 seconds, $60^{\circ} \mathrm{C}$ for 30 seconds, $68^{\circ} \mathrm{C}$ for 1 minute and a final termination step at $68^{\circ} \mathrm{C}$ for 10 minutes. $\beta$-actin was amplified as a control (Forward: 5'-TCAAACGAACGACCAACC-3'; Reverse: 5'-AGACACCCTGGCTTACAT-3'), and negative control reactions lacked either reverse transcriptase or cDNA template. The PCR products were visualized by agarose gel electrophoresis.

\subsection{Anti-PI synthase polyclonal antiserum generation}

An anti-PI synthase polyclonal antisera was generated against a C-terminal zebrafish PI synthase peptide (NP_996971; SRNMAAIDVADREKERSKAQ) that was synthesized in 
vitro, conjugated to $\mathrm{KLH}$, and injected into rabbits using a standard immunization protocol (Proteintech Group; Chicago, IL). The PI synthase antisera were purified by affinity chromatography. The genomic region corresponding to the last twenty amino acids of the cdipt-encoded protein was PCR amplified with primers possessing internal BamHI and XhoI restriction sites (Forward: 5'-GGATCCCTCATCACCGCTTCC-3'; Reverse: 5'CTCGAGCTATGTGCTCATGTC-3') and cloned into the TOPO vector (Invitrogen). The fragment was subcloned into the pET32a expression vector (Novagen; San Diego, CA) and expression of the fusion protein was induced with IPTG in BL21 (DE3) cells (Novagen). Gel-purified PI synthase fusion protein was covalently coupled to a column matrix (AminoLink Plus Immobilization, Pierce; Rockford, IL). Crude anti-PI synthase serum was first passed through a previously generated non-specific column matrix according to the manufacturer's protocol. The resulting flow-through fraction was affinity purified over the PI synthase-specific column. Immunoblots and frozen tissue sections from wild-type and cdipt morphants demonstrated the specific knockdown of the PI synthase protein and confirmed antiserum specificity and reactivity.

\subsection{Immunoblot analysis}

Protein was isolated from 20 embryos for each experimental group: $6 \mathrm{dpf}$ wildtype, $6 \mathrm{dpf}$

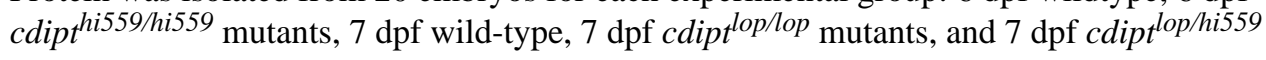
trans-heterozygotes. Tissues were homogenized in $3 \mu \mathrm{l}$ extraction buffer/embryo, which consisted of PBS/10\% Glycerol/1 \% Triton X-100/5 mM KPO $4 / 0.05 \mathrm{mM}$ EDTA/1x Complete Protease Inhibitor Cocktail Tablet (Roche; Basel, Switzerland). Immunoblot analysis was performed as previously described (Vihtelic et al. 1999; Shi et al. 2005). Protein aliquots were combined with sample loading buffer and reducing agent, heated to $90^{\circ} \mathrm{C}$ for 5 minutes, and electrophoresed through a $15 \%$ SDS-PAGE gel according to a standard protocol (Novex Tris-Glycine Gel Systems, Invitrogen). Proteins were transferred to a PVDF H-Bond membrane (Amersham; Piscataway, NJ) and blocked in PBS/0.1\% Tween-20/5\% nonfat dry milk for at least an hour. The membrane was incubated with either an anti-PI synthase antibody (1:250) or an anti-actin monoclonal antibody (1:10,000, Calbiochem; San Diego, CA) overnight at $4^{\circ} \mathrm{C}$ in blocking buffer. The membrane was washed in PBS/0.1\% Tween-20, and incubated with an anti-rabbit or anti-mouse HRPconjugated secondary antibody (1:10,000, Amersham). The ECL-Plus system (Amersham) was used to detect the secondary antibody as described (Vihtelic et al. 1999).

\section{Results}

\subsection{The zebrafish lop mutation is a cdipt missense allele}

The zebrafish lens opaque (lop) mutant was previously identified in an ENU-induced mutagenesis screen for eye morphological mutants (Vihtelic and Hyde 2002; Vihtelic et al. 2005). The homozygous lop mutant exhibits lens opacity, or cataract, at 7 days post fertilization (dpf) relative to wild-type siblings (Fig. 1, panels B and A, respectively; Vihtelic et al. 2005). At $7 \mathrm{dpf}$, coronal sections of lop mutant eyes revealed that the lens secondary fiber cells lacked structural organization with the neighboring lens cortex and often contained intracellular organelles (Fig. 1D, arrow). The lop mutant lens epithelial cells at the distal surface also lacked the characteristic monolayer organization and cuboidal morphology (Fig. 1D, double arrowheads). While wild-type larvae possessed a full complement of mature photoreceptor cells, the lop mutant retina lacked any definitive photoreceptor layer (Fig. 1, panels C and D, respectively, single arrowhead). Additionally, the lop eye was, in general, smaller than the wild type eye. The lop mutant, however, was phenotypically indistinguishable from wild-type siblings at $4 \mathrm{dpf}$, suggesting that early eye development occurred normally (Vihtelic et al. 2005). 
Recombination mapping placed the lop mutation on chromosome 3, in the interval found on DKEY-183N6 (Supplemental Fig. 1). This region contains seven transcriptional units, including the cdipt gene (CDP-diacylglycerol:myo-inositol 3-phosphatidyltransferase). The cdipt $^{h i 559 / h i 559}$ mutation, which was identified in a retroviral-insertional mutagenesis screen (Amsterdam et al. 2004), possesses a retroviral insertion in the first intron of the cdipt gene (Fig. 1L). While the $c d i p t^{h i 559 / h i 559}$ mutant was histologically similar to the $c d i p t^{l o p / l o p}$ mutant and was smaller in size like the $c$ dipt $t^{\text {lop/lop }}$ mutant (Fig.1, panels F and D, respectively), there were some notable differences. First, the ddipt $^{\text {hi559/hi559 }}{ }^{\text {mutant }}$ exhibited lens opacity between 5 and $6 \mathrm{dpf}$, rather than $7 \mathrm{dpf}$ for the $c d i p t^{l o p / l o p}$ mutant (data not shown). Second, the $c d i p t^{h i 559 / h i 559}$ mutant exhibited histological defects, such as a disruption of the lens organization and loss of the photoreceptor layer by $6 \mathrm{dpf}$ instead of 7 dpf for the $c$ dipt $t^{\text {lop/lop }}$ mutant (Fig. 1, panels E and D, respectively). Finally, the cdipt $^{\text {hi559/hi559 }}$ lens degenerated more rapidly than the $c$ dipt $t^{\text {lop/lop }}$ mutant (Fig. 1, panels $\mathrm{F}$ and $\mathrm{D}$, respectively). Thus, the $c d i p t^{h i 559 / h i 559}$ mutant appeared to possess more severe mutant phenotypes than the $c$ dipt $t^{\text {lop/lop }}$ mutant.

To determine if lop is a cdipt allele, $c$ dipt ${ }^{\text {lop/hi559 }}$ trans-heterozygotes were generated and found to possess comparable lens and retinal phenotypes as either the $c d i p t^{l o p} / l o p$ or cdipt $^{\text {hi559/hi559 }}$ mutants (Fig. 1, compare panels G and H to panels D-F, respectively). The cdipt $^{\text {lop/hi559 }}$ trans-heterozygous mutants exhibited lens and retinal phenotypes by 6 dpf like the $c d i p t^{h i 559 / h i 559}$ mutant (Fig. 1, panels G and E, respectively) and possessed the pronounced lens degeneration by $7 \mathrm{dpf}$ that was observed in the $c d i p t^{h i 559 / h i 559}$ mutant (Fig. 1 , panels $\mathrm{H}$ and $\mathrm{F}$, respectively). The apparently more severe lens phenotypes in the

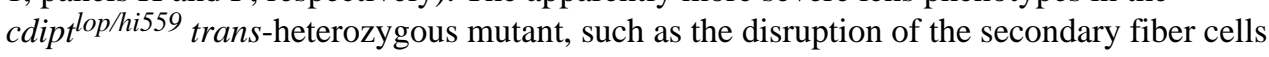
at $6 \mathrm{dpf}$ and the large increase of cells anterior to the lens at $7 \mathrm{dpf}$ (Fig. 1, panels $\mathrm{G}$ and $\mathrm{H}$, respectively), were within the phenotypic range that was also observed for the cdipt $t^{\text {hi559/hi559 }}$ mutant. Thus, the histology of the $c$ dipt $t^{\text {lop/hi559 }}$ trans-heterozygous demonstrated that the lop mutation is a cdipt allele.

We sequenced the $c$ dipt $^{\text {lop }}$ allele and found that it contained a single missense mutation relative to the wild-type sequence, an adenine to thymine change at position 331 in the third exon (Fig. 1L). This mutation resulted in a serine-to-cysteine amino acid substitution at the invariant position 111, which is located in the catalytic domain of the 213 amino acid phosphatidylinositol (PI) synthase enzyme (Supplemental Fig. 1C, red arrowhead). In contrast, the $c$ dipt ${ }^{h i 559}$ retroviral insertion in the first intron would disrupt the PI synthase amino acid sequence near the amino terminus (Fig. 1L and Supplemental Fig. 1C, yellow arrowhead). These mutations are consistent with the $c d i p t^{h i 559}$ allele being more severe than cdipt $^{\text {lop. }}$

\subsection{Reduced expression of the cdipt-encoded protein accounts for the lens and retinal mutant phenotypes}

To phenocopy the $c$ dipt $t^{l o p / l o p}$ mutant phenotype, lissamine-tagged antisense morpholino oligonucleotides complementary to the exon 2:intron 2 splice junction (MO2) of the cdipt gene were microinjected into 1-4 cell stage wild-type embryos. At 3 dpf, mRNA was isolated and pooled from several lissamine-positive morphants and age-matched wild-type control larvae for cDNA generation, while independent pools were used for histology. RTPCR primers were used to detect both the correctly spliced wild-type cDNA and the spliceinhibited morphant cDNA (Fig. 1K, $330 \mathrm{bp}$ and $196 \mathrm{bp}$, respectively). At $7 \mathrm{dpf}$, the cdipt MO2 morphant possessed a small eye, nucleated cells in the lens nucleus, disorganized secondary lens fiber cells and lens epithelial cells, and a small number of immature photoreceptors that lacked outer segments in the central retina (Fig. 1J). None of these phenotypes were observed in either the wild-type eye or the 5-base mismatch cdipt MO2 (cdipt 5-mis MO2) morphant eye (Fig. 1, panels C and I, respectively). However, the MO2 
morphant exhibited a much smaller eye than the $c$ dipt mutants, a less severe retinal phenotype than the cdipt mutants (centrally-located immature photoreceptors compared to no photoreceptors), and a different lens phenotype than the cdipt mutants. Therefore, we knocked down PI synthase using an independent translation-blocking morpholino (MO1; Supplemental Fig. 2B), which resulted in a morphant eye that was phenotypically similar to the cdipt MO2 morphant retina (Supplemental Fig. 2D and Fig. 1J, respectively). While both morphants exhibited eye phenotypes (small eye, centrally-located immature photoreceptors) that were not observed in any of the cdipt mutant eyes (Fig. 1, panels D, F, and $\mathrm{H}$ ), the presence of both retinal and lens phenotypes in the morphants further suggested that the cdipt $^{l o p}$ mutant phenotypes were due to a defect in PI synthase.

To further support that loss of PI synthase caused the lop mutant ocular phenotypes, we microinjected either water or $50 \mathrm{ng} / \mu \mathrm{l}$ of in vitro transcribed wild-type $c$ dipt ${ }^{+}$mRNA into 1-4 cell stage embryos resulting from a heterozygous $c$ dipt $t^{l o p /+}$ pairmating. At $7 \mathrm{dpf}$, both uninjected and water-injected embryos yielded the expected $25 \%$ of larvae from a heterozygote pairmating with the recessive mutant lens phenotype (Table 1). In contrast,

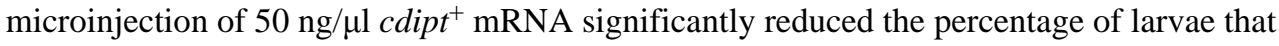
displayed the mutant lens opacity phenotype relative to the control larvae (Table 1). These data confirmed that reduced expression of the cdipt-encoded wild-type protein results in the mutant lens phenotype.

\subsection{Histological examination of $c d i p t^{h i 559 / h i 559}$ prior to gross lens opacification reveals early retinal abnormalities}

To examine the onset of cdipt mutant phenotypes, we PCR genotyped $c d i p t^{\text {hi555/hi559 }}$ individuals from heterozygous $c d i p t^{h i 559 /+}$ pairmatings and histologically characterized the resulting ocular phenotypes beginning at $3 \mathrm{dpf}$. Individual larvae were bisected, with the heads processed for histology and the bodies for genomic DNA isolation and PCR genotyping. Due to the retroviral insertion within the $c d i p t^{h i 559}$ allele, PCR amplification of genomic DNA unambiguously identified homozygous wild-type, heterozygous carriers and homozygous mutant larvae based on the presence of a $330 \mathrm{bp}$ wild-type and/or a $191 \mathrm{bp}$ cdipt $^{h i 559}$ product (Fig. 2A).

The cdipt $^{h i 559 /+}$ heterozygous phenotype was indistinguishable from the wild-type phenotype at all time points analyzed (data not shown). At 3 dpf, the $c d i p t^{h i 559 / h i 559}$ homozygous mutant eye possessed all the retinal layers similar to wild-type eyes (Fig. 2, panels $\mathrm{C}$ and $\mathrm{B}$, respectively). Unlike the wild-type retina, however, the rods and cones in the $c$ dipt hi559/hi559 mutant were disorganized and contained small, darkly stained nuclei (Fig. 2, panels E and D, respectively), which could represent pyknotic nuclei. The $c d i p t^{h i 559 / h i 559}$ lens, similar to wild-type (Fig. 2, panels $\mathrm{G}$ and F, respectively), contained an organelle-free nucleus, possessed differentiating secondary fiber cells, and had an intact monolayer of cuboidal-shaped lens epithelial cells (Fig. 2, panels F and G, double arrowheads). This suggests that early events required for lens development, such as delamination of the lens mass, differentiation of primary and secondary fiber cells, and the initial proliferation of the secondary fiber cells occurred normally. Thus, the earliest histological defects in the cdipt $t^{\text {hi559/hi559 }}$ eye were detected in the photoreceptor layer at $3 \mathrm{dpf}$.

By 5 dpf, wild-type rods and cones had differentiated and begun to extend their outer segments (Fig. 3C, single arrowhead), while the $c d i p t^{h i 559 / h i 559}$ mutant lacked a definitive photoreceptor layer, with both rod and cone nuclei missing (Fig. 3D, single arrowhead). This is consistent with the absence of photoreceptors at the transmission electron microscopy level in the $7 \mathrm{dpf} c$ dipt $^{l o p}$ mutant retina (Vihtelic et al. 2005). At $5 \mathrm{dpf}$, the $c d i p t^{\text {hi559/hi559 }}$ mutant lens phenotype first appeared. Secondary fiber cell differentiation and lens epithelial cell organization were disrupted relative to control eyes (Fig. 3, panels F and E, 
respectively). However, the $c d i p t^{h i 559 / h i 559}$ lens nucleus remained intact and free of intracellular organelles similar to control lenses (Fig. 3, panels F and E, respectively).

We previously demonstrated that the $c$ dipt $t^{l o p}$ mutant also lacked rhodopsin, UV opsin, and red opsin expression at $7 \mathrm{dpf}$ based on immunolocalization (Vihtelic et al. 2005). In contrast, HuC/D-positive amacrine and ganglion cells, PKC-positive bipolar cells, and glutamine synthetase-positive Müller glia were present in normal number and location in the cdipt $^{\text {lop }}$ mutant retina at $7 \mathrm{dpf}$ (Vihtelic et al. 2005). We examined if the absence of photoreceptor cells in cdipt ${ }^{h i 559 / h i 559}$ mutant histological sections was accurate. By 6 dpf, immunohistochemical staining confirmed that rhodopsin-positive rods, blue opsinexpressing long single cones and ultraviolet opsin-expressing cones were absent in the cdipt ${ }^{\text {hi559/hi559 }}$ retinas (Fig. 4, panels E, F and G, respectively), but present in wild-type retinas (Fig. 4, panels A, B and C, respectively). Furthermore, Zpr-1, which corresponds to an arrestin 3-like protein that is expressed in double cone cell bodies (Ile et al. 2010), was detected in wild-type retinas, but not in cdipt $^{h i 559 / h i 559}$ mutant retinas (Fig. 4, panels D and $\mathrm{H}$, respectively). Consistent with what was previous described for the cdipt $t^{l o p}$ mutant retina (Vihtelic et al. 2005) and in retinas possessing dying photoreceptors, the $c$ dipt $t^{\text {hi559/hi559 }}$ mutant possesses PCNA-positive cells in both the retinal margin and the inner and outer nuclear layers of the central retina, but only in the retinal margin of wild-type eyes (Fig. 4, panels E and A, respectively).

We also examined if the additional cells that were associated with the $c d i p t^{h i 559 / h i 559}$ mutant lens were derived from the lens or some other tissue. We immunostained both wild-type and mutant lenses with monoclonal antibody $\mathrm{Zl}-1$, which is expressed in wild-type secondary lens fiber cells (Fig. 4B, arrowhead). We found that the Zl-1 antigen was also present in the disorganized cells associated with the $c$ dipt ${ }^{h i 559 / h i 559}$ mutant lens (Fig.4F arrowhead). This suggests that the mass of cells associated the $c d i p t^{h i 559 / h i 559}$ mutant lens at least express secondary lens fiber cell proteins.

\subsection{Photoreceptor cell death precedes lens cell apoptosis in the cdipt ${ }^{\text {hi559/hi559 }}{ }^{\text {mutant }}$}

To investigate the basis of photoreceptor cell loss and lens cell disruption (Fig. 5), progeny from a cdipt $^{h i 559 /+}$ heterozygous pair-mating were analyzed for cell death. Frozen sections were immunolabeled with TUNEL and $\alpha \mathrm{A}$-crystallin to label apoptotic cells and newly differentiated secondary lens fiber cells, respectively. At $3 \mathrm{dpf}$, there were no significant differences between wild-type and cdipt $t^{h i 559 / h i 559}$ mutant retinas and lenses (Fig. 5, panels A and B, respectively). At $4 \mathrm{dpf}$, cdipt $t^{h i 559 / h i 559}$ larvae displayed an increased number of TUNEL-positive cells within the retinal photoreceptor layer relative to the control retina (Fig. 5, panels D and C, respectively; arrows), with no significant differences between the mutant and wild-type lenses. However, a large increase in the number of TUNEL-positive cells was observed in both the mutant retina and lens at $5 \mathrm{dpf}$ (Fig. 5F, arrows and arrowheads, respectively) relative to wild-type (Fig. 5E), suggesting that the observed photoreceptor cell loss is attributed to cell death rather than developmental absence. $\alpha \mathrm{A}$ crystallin labeling revealed a relatively wild-type appearing population of new secondary fiber cells in the $c$ dipt $t^{h i 559 / h i 559}$ mutant larvae at $4 \mathrm{dpf}$ (Fig. 5D), which started to exhibit perturbations as TUNEL-positive cells appeared at $5 \mathrm{dpf}$ (Fig. 5F). This suggested that the mutant lens initially developed normally, but does not distinguish if secondary fiber cell death disrupts lens cell organization or if perturbing the secondary fiber cells arrangement leads to their death between 4 and $5 \mathrm{dpf}$.

\subsection{Spatial and temporal analysis of cdipt expression}

The temporal expression of the wild-type $c$ dipt gene was examined by RT-PCR of polyA ${ }^{+}$ mRNA isolated throughout early development. The 877 bp $c$ dipt RT-PCR product amplified 
at $3 \mathrm{hpf}$ suggested that the $c$ dipt transcript was maternally inherited (Fig. 6A), because zygotic transcription does not begin until after this timepoint. The cdipt product was also detected through $48 \mathrm{hpf}$ (Fig. 6A), demonstrating that the gene continued to be expressed throughout early development. Additionally, the RT-PCR product was observed in a wide variety of adult tissues, including both the lens and retina (Fig. 6B), suggesting broad temporal and spatial expression patterns. We examined if the mutants and morphants exhibited broad phenotypic abnormalities at either $6\left(\right.$ cdipt $\left.^{\text {hi555/hi559 }}\right)$ or $7 \mathrm{dpf}\left(c d i p t^{l o p} / l o p\right.$, MO1, and MO2). While both mutants and morphants exhibited small eyes, cloudy and defective lenses, and abnormal jaw structures, the general brain structures appeared to be relatively normal (Supplemental Figure 3). While broad developmental abnormalities may not be apparent at the histological level, cellular and subcellular defects may still exist in these mutants and morphants.

To examine the expression of the PI synthase protein, we generated a rabbit anti-PI synthase polyclonal antiserum. To confirm the specificity of the anti-PI synthase polyclonal antiserum, we performed an immunoblot to examine the expression of the deduced $24 \mathrm{kDa}$ PI synthase protein. The anti-PI synthase antiserum recognized a $21 \mathrm{kDa}$ protein on immunoblots in both 6 and $7 \mathrm{dpf}$ wild-type extracts, which was not detected in either the cdipt $t^{\text {hi559/hi559 }}$ or $c$ dipt ${ }^{\text {lop/lop }}$ mutants or the trans-heterozygote (Fig. 7A). This suggests that the mutant PI synthase proteins are either very unstable or rapidly degraded. Alternatively, the cdipt $^{\text {hi559/hi559 }}$ mutant mRNA may undergo nonsense-mediated decay, which would also lead to a significant reduction in the mutant protein. The broad spatial distribution of the cdipt transcript (Fig. 6B) was confirmed by immunolocalizing the protein in the brain (asterisk), retina (double asterisk), and lens (arrowhead) of the wild-type head at 6 and $7 \mathrm{dpf}$ (Fig. 7, panels B and D, respectively). In contrast, both the $c d i p t^{h i 559 / h i 559}$ and $c d i p t^{l o p / l o p}$ tissue sections (Fig. 7, panels C and E, respectively) possessed reduced PI synthase immunostaining in the brain and retinal tissues (asterisk and double asterisk, respectively) relative to the wild-type tissue sections. The residual immunostaining in the mutant lens (Fig. 7, panels $\mathrm{C}$ and $\mathrm{E}$, arrowheads) was due to non-specific fluorescence within the damaged tissue based on negative controls that lacked the primary antisera (Fig. 7E'). Taken together, cdipt exhibits a broad temporal and spatial expression patterns throughout the developing zebrafish embryo and into adulthood.

We used this polyclonal antiserum to immunolocalize the PI synthase protein in the developing wild-type eye. At 24 hpf, PI synthase is already detected in the lens placode (Fig. $8 \mathrm{~A}$ ). From 36 through $72 \mathrm{hpf}$, PI synthase is detected at low levels in the developing retina and the adjacent brain (Fig. 8, panels B-E), including the differentiating photoreceptor layer (Fig. 8, panels D and E, arrow). At these same time points, PI synthase is detected at a higher level in the developing lens nucleus (Fig. 8, panels B and C), followed by the preferential expression in the lens secondary fiber cells and lens epithelial cells (Fig. 8, panels $\mathrm{D}$ and $\mathrm{E}$, double arrowheads). By $7 \mathrm{dpf}$, expression in the retina, including the photoreceptors, increases and begins to approximate the level of expression in the lens secondary fiber cells (Fig. 8F). To confirm that these broad retinal and lens immunostaining patterns are specific for the PI synthase antiserum, a $7 \mathrm{dpf}$ wild-type eye that was stained in the absence of the primary anti-PI synthase polyclonal antiserum showed no signal in the retina and only very weak background fluorescence in the secondary fiber cells (Fig. 8G, same exposure settings as panel F).

In the adult eye, PI synthase expression is present in both the outer nuclear layer rods and the adjacent cones and the inner nuclear layer secondary neurons (Fig. 8, panels $\mathrm{H}$ and I). In the adult lens, PI synthase was detected in both the nucleus and the more recent secondary lens fiber cells (Fig. 8J). To confirm that this lens immunostaining pattern is specific for the PI synthase antiserum, a wild-type lens that was stained in the absence of the primary anti-PI 
synthase polyclonal antiserum showed very weak background fluorescence in the secondary fiber cells and not in the nucleus (Fig. 8K, same exposure settings as panel J). Thus, PI synthase expression begins early in the development of the eye and persists throughout the retina and the lens into adulthood.

\subsection{The zebrafish cdipt gene encodes an active PI synthase}

To demonstrate that the zebrafish $c$ dipt gene encodes a functional PI synthase, we examined whether zebrafish cdipt expression could rescue the lethality associated with deletion of the single essential yeast PI synthase gene (PISl). This heterologous yeast phenotypic complementation assay involved expressing the zebrafish $c$ dipt gene from the episomal pDR195 plasmid in heterozygous PIS1/pis14::KanMx diploid yeast and monitoring the fate of pis $14: \because K a n M x$ meiotic progeny that inherited the expression plasmid (phenotypically marked by Ura prototrophy $-\mathrm{Ura}^{+}$).

All of the four-spore tetrads analyzed from the PIS1/pis14:KanMx heterozygous diploid strain containing the pDR195 control vector exhibited a segregation pattern of 2 viable:2 nonviable meiotic progeny on YPD medium (Fig. 9A, top row). Additionally, all of the viable progeny $\left(\mathrm{PISI}^{+}\right)$were $\mathrm{G} 418^{\mathrm{s}}$ (Fig. 9A, bottom row) - reporting that the viable progeny failed to inherit the pis $14:$ KanM $x$ allele (Fig. 9B). These data confirmed that pis14: KanMx is a haploid lethal allele whose lethal phenotype is indifferent to inheritance of the pDR195 control vector. In contrast, six of the ten four-spore tetrads carrying the pDR195/cdipt vector exhibited a segregation pattern of 4 viable: 0 nonviable meiotic progeny on YPD medium (Fig. 9A). In all six cases, a 2:2 segregation of G418 $8^{\mathrm{r}}$ G418 $8^{\mathrm{s}}$ and 4:0 segregation of $\mathrm{Ura}^{+}: \mathrm{Ura}^{-}$phenotypes was recorded. Indeed, all six of these tetrads exhibited proper Mendelian segregation for all other markers in the crosses, demonstrating the fidelity of the meioses. Notably, of the remaining four tetrads, two displayed a segregation of 3 viable: 1 nonviable spore. In all those cases, at least one of the viable segregants was G418 and all G418 ${ }^{\mathrm{r}}$ segregants were also $\mathrm{Ura}^{+}$. That is, no G418r ${ }^{\mathrm{r}} \mathrm{Ura}^{-}$ segregants were recovered. The last two tetrads yielded 2 viable progeny apiece, and in all cases these viable progeny recovered were G418 - i.e. genotypically PISI (data not shown). Taken together, these segregation patterns demonstrated recovery of viable pis $1 \Delta: \because K a n M x$ haploids upon co-inheritance of the plasmid-borne zebrafish cdipt (Fig. 9A).

The phenotypic results were confirmed by PCR-based genotyping of progeny derived from a representative control tetrad, and a tetrad which exhibited a 4:0 segregation of viable:nonviable meiotic progeny. For the PIS1/pis14:KanMx heterozygous diploid strain carrying pDR195, both viable progeny recovered from the dissected tetrad genotyped as PIS1. As expected, these failed to amplify the zebrafish cdipt sequence (Fig. 9B). In contrast, the pDR195/cdipt vector was present in all four viable meiotic progeny in the test cross as evidenced by positive amplification of the zebrafish sequence from all of the corresponding template samples. Moreover, the pis $14: \because K a n M x$ allele (but not PIS1) was recovered from both viable G418 ${ }^{\mathrm{r}}$ segregants, and only PISI was amplified from DNA extracted from the two G418 haploids (Fig. 9B). These collective data definitively demonstrate that zebrafish $c$ dipt $t^{+}$expression rescued pis $14: \because K a n M x$ lethality. We take this as unambiguous evidence that $c d i p t^{+}$encodes PI synthase activity.

\section{Discussion}

In this study, we extended our analysis of the zebrafish lens opaque mutant (cdipt ${ }^{\text {lop/lop }}$ ) phenotype, which displayed lens opacity and photoreceptor apoptosis at $7 \mathrm{dpf}$ (Vihtelic et al. 2005). We determined that the lop mutation corresponded to a cdipt allele based on: i) DNA sequence analysis that revealed a missense mutation that changed a conserved serine in the PI synthase catalytic domain to a cysteine, ii) a cdipt morphant yielded retinal and lens 
phenotypes that were more severe than the lop mutant phenotype, iii) in vitro transcribed wild-type $c$ dipt mRNA rescued the lop mutant phenotype, iv) the lop mutation failed to complement the previously identified $c d i p t^{h i 559}$ allele, which contains a viral insertion in the first intron of the cdipt gene (Amsterdam et al. 2004). As expected from these molecular data, the $c_{\text {dipt }}{ }^{l o p}$ allele is likely a hypomorphic allele, as its phenotypes are less severe (based on the age when the phenotypes are first observed) relative to the $c d i p t^{h i 559}$ allele.

Surprisingly, both cdipt morphants exhibited retinal and lens phenotypes that were similar, but more severe, than either $c$ dipt mutants. The extremely small eye size and immaturelooking retina in the morphants relative to the cdipt mutants could be attributed to a general developmental delay that is often observed with morpholinos, however, neither phenotype was present in the cdipt 5-mis MO2 morphant retina. It is also possible that the more severe phenotype in the MO1 morphant could be a result of knocking down the translation of maternally-loaded cdipt mRNA, however, this does not explain the severe phenotype in the splice-blocking MO2 morphant. Another possibility is that neither $c d i p t^{l o p}$ or $c d i p t^{\text {his59 }}$ are true null alleles and that both morphants significantly knockdown PI synthase expression and activity to a greater extent than either mutant. Finally, the more severe effects observed in the morphants may be a combination of the above effects. However, the appearance of both the lens and retinal phenotypes in the mutants, regardless of their severity, is further support that the lop mutant phenotypes are due to a mutation in the cdipt gene.

Because the same eye phenotypes were observed in both alleles, disruption of lens development and death of photoreceptors, we focused our phenotypic characterization on the $c$ dipt $t^{h i 559}$ mutant because we could unambiguously genotype the $c d i p t^{h i 559}$ allele using PCR amplification before cellular phenotypes were observed. We demonstrated that the cdipt ${ }^{h i 559 / h i 559}$ lens developed properly through $3 \mathrm{dpf}$ (Fig. 2G), with an intact lens nucleus composed of organelle-free primary fiber cells, a monolayer of epithelial cells at the distal surface, and newly differentiated secondary fiber cells forming the lens cortex (Easter and Nicola 1996; Soules and Link 2005; Dahm et al. 2007). The cdipt ${ }^{h i 559 / h i 559}$ mutant, however, already displayed a disorganized photoreceptor layer containing pyknotic nuclei at $3 \mathrm{dpf}$ (Fig. 2E), at a time when the wild-type zebrafish retina possesses all the cell types and laminar organization found in the mature retina (Fig. 2D; Raymond et al. 1995; Easter and Nicola 1996; Schmitt and Dowling 1996; Schmitt and Dowling 1999). By 5 dpf, the cdipt $t^{\text {hi559/hi559 }}$ mutant lacked a definitive outer nuclear layer (Fig. 3D). This loss of photoreceptor cells correlated with increased number of TUNEL-positive nuclei in the outer nuclear layer through $5 \mathrm{dpf}$ (Fig. 5). Additionally, the increased cell proliferation that we observed in the $c$ dipt $t^{l o p / l o p}$ mutant retina (Vihtelic et al. 2005) likely resulted from this photoreceptor cell death, which is known to induce a proliferative regeneration response in the adult zebrafish retina (Vihtelic and Hyde 2000).

In contrast, the $c d i p t^{h i 559 / h i 559}$ mutant lens phenotype was not evident until 5 dpf (Fig. 3F), when we observed disorganized lens secondary fiber cells, a disrupted monolayer of cuboidal epithelial cell nuclei, and nucleated cells accumulating at the distal lens surface that lacked their normal cell adhesion. The cdipt mutant also possessed an increased number of proliferating cells distal and lateral to the lens, suggesting that the mutant exhibited misregulation of epithelial cell proliferation that resulted in the accumulation of nucleated cells at the distal lens surface. Previously, we suggested that the loss of photoreceptors was secondary to the disruption of the lens (Vihtelic et al. 2005). However, the appearance of a retinal phenotype prior to the observed lens phenotype suggests that either the retinal phenotype is not a result of the lens defect or the underlying molecular defects are still not apparent. 
The zebrafish bumper (bum) mutant, which was previously identified in a large scale ENUmutagenesis screen (Heisenberg et al. 1996), exhibits many phenotypes that are similar to the cdipt mutant. Histology of the bum mutant revealed hyperproliferation of undifferentiated lens epithelial cells at $3 \mathrm{dpf}$, resulting in the accumulation of a disorganized cell mass in the anterior chamber at $4 \mathrm{dpf}$, which then decreased by $5 \mathrm{dpf}$ (Schonthaler et al. 2010). Similarly, we found a large increase in the number of undifferentiated epithelial cells in the cdipt $^{\text {hi }} 559 / \mathrm{hi} 559$ mutant as early as $5 \mathrm{dpf}$ (Figure 3F), but it never decreased. Both the cdipt mutant and the bum mutant exhibited defects in secondary fiber cell differentiation resulting in lens cortex degeneration. At $4 \mathrm{dpf}$, the bum secondary fiber cells appeared swollen, with vacuoles appearing amongst the cortical fibers by $5 \mathrm{dpf}$, which is similar to the secondary fiber cell unpacking in the cdipt mutant (Figure 1). While the $c$ dipt mutant exhibited rod and cone photoreceptor cell loss, the bum mutant possessed all the retinal layers and cell types into adulthood, suggesting that the bum mutant phenotype is truly lens specific. SSLP mapping localized the bum mutation to a critical region on chromosome 7 (Schonthaler et al. 2010), clearly ruling it out as being a cdipt allele, which is located on chromosome 3. Three genes within the critical region of the bum mutation, hspal2b, $s l c 8 a 4 b$ and $c c t 7$, were sequenced as potential candidates, but none of the genes contained a mutation within the open reading frames (Schonthaler et al. 2010). However, the authors also identified a gene encoding a protein similar to human phospholipase C- $\beta$ (PLC $\beta$ ) within this critical region (Schonthaler et al. 2010). In light of the similarity to the $c$ dipt lens phenotype and the role of $c d i p t$ in PI metabolism, the PLC $\beta$ gene is a viable candidate for bum.

We previously demonstrated that transplanting a cdipt lop/lop lens into a wild-type eye at 31 hpf induced both the lens and retinal defects, while transplanting a wild-type lens into a cdipt lop/lop eye at the same time yielded a normal lens and a mutant retina (Vihtelic et al. 2005). While the latter result demonstrated that the cdipt-encoded PI synthase is required cell autonomously in the photoreceptors, the former transplantation experiment suggested that the lens must also secrete a signal that is required for photoreceptor survival (Vihtelic et al. 2005). Phosphatidylinositol (PI) is the precursor to at least seven different phosphoinositides that function in multiple signaling networks to affect various cellular processes, including cell differentiation and cell cycle regulation (Payrastre et al. 2001; Payrastre 2004). While the cell-autonomous requirement for PI biosynthesis in photoreceptor cell survival appears obvious, the PI-dependent signal generated by the lens to maintain the photoreceptors remains unknown.

By rescuing the lethality associated with deletion of the single yeast PI synthase gene (PIS1), we confirmed that the zebrafish cdipt gene encodes the PI synthase enzyme, which catalyzes the condensation of myo-inositol and CDP diacylglycerol to generate phosphatidylinositol (Antonsson 1997; Lykidis et al. 1997; Payrastre et al. 2001; Vanhaesebroeck et al. 2001). In the developing chick lens, increased PI synthesis was associated with the fiber cell formation (Zelenka 1980), while stimulating proliferation of cultured chick lens epithelial cells increased the rate of PI turnover (Zelenka and Vu 1984). This suggests that PI metabolism may regulate the cell cycle in mitotically active lens epithelial cells.

However, it is known that PI3 kinase mediates neuronal survival in the mouse retina (Pimentel et al. 2002), such that the photoreceptor cell death in the $r d$ mouse is, in part, dependent upon inactivating the PI3 kinase/Akt pathway (Portera-Cailliau et al. 1994; Jomary et al. 2006). Further analysis of PI cycle defects in the cdipt mutant eyes may help elucidate the role phosphoinositides play in zebrafish photoreceptor development and maintenance. 
It is known that PI3 kinase plays a critical role in the lens. For example, inhibiting PI3 kinase activity suppressed rabbit lens epithelial cell proliferation and stimulated the synthesis of early differentiation markers in chick lens epithelial cells (Chandrasekher and Sailaja 2003). Additionally, inhibiting PI3 kinase suppressed lens cell differentiation in primary quail lens cell culture (Weber and Menko 2006), and activated glycogen synthase kinase-3 (GSK3) to drive apoptosis in differentiating lens fiber cells (Weber and Menko 2006). These data implicate the importance of the PI cycle in lens cell proliferation, differentiation, and cell survival.

Recent studies also implicated the PI3 kinase pathway in cataract formation (Chandrasekher and Sailaja 2004; Cho et al. 2007; Yao et al. 2008), such as the significant reduction in PI3 kinase activity in selenite cataracts in rats (Chandrasekher and Sailaja 2004). Inhibiting PI3 kinase activity also blocked TGF- $\beta$-induced epithelial-to-mesenchymal transitions (EMT) in the mouse lens, which has been widely implicated in some models of cataract formation (de Iongh et al. 2005; Shirai et al. 2006), based on reduced expression of the myofibroblast marker $\alpha$-smooth muscle actin and maintenance of cuboidal, rather than myofibroblast-like, lens epithelial cell morphology (Cho et al. 2007). We also observed the loss of the cuboidal lens epithelial cell morphology in the cdipt mutants, perhaps indicating an EMT event within the $c$ dipt mutant lenses.

Many human cataract conditions are also typified by abnormal lens cell EMT resulting in fibrotic cells that contribute to the scattering of light (de Iongh et al. 2005). The fibrotic cell accumulation at the anterior surface, deregulation of epithelial cell proliferation and differentiation, and aberrant lens fiber cell differentiation characterize the human anterior subcapsular cataract (ASC) condition (Nagamoto et al. 2000; Lovicu et al. 2004a; Lovicu et al. 2004b; de Iongh et al. 2005). Similarly, our zebrafish cdipt mutants show an accumulation of nucleated cells at the distal lens surface, misregulation of lens epithelial cell proliferation, and defects in fiber cell differentiation. Thus, the zebrafish cdipt mutants may serve as a model for some of the features of ASC. Human oculocerebrorenal syndrome of Lowe (OCRL), which is caused by a mutation in the $\mathrm{PI}_{(4,5)}-\mathrm{P}_{2}$ 5-phosphatase, displays congenital cataracts and demonstrates the precedence for altering the PI cycle leading to a human cataract condition (Attree et al. 1992). Thus, the zebrafish cdipt mutants represent an unique opportunity to model in vivo the role of the PI cycle in a variety of diseases that lead to cataract formation.

\section{Supplementary Material}

Refer to Web version on PubMed Central for supplementary material.

\section{Acknowledgments}

We thank D. Bang and the staff of the Freimann Life Science Center for Providing zebrafish husbandry and care. This work was funded by National Institutes of Health grant R01 EY014455 (T.S.V.) and the Center for Zebrafish Research at the University of Notre Dame. KEI and VAB were supported by National Institutes of Health grant R01 GM44530 (V.A.B.).

\section{References}

Amsterdam A, Nissen RM, Sun Z, Swindell E, Farrington S, Hopkins N. Identification of 315 genes essential for early zebrafish development. Proc Natl Acad Sci USA. 2004; 101:12792-12797. [PubMed: 15256591]

Antonsson B. Phosphatidylinositol synthase from mammalian tissues. Biochim Biophys Acta. 1997; 1348:179-186. [PubMed: 9370331] 
Attree O, Olivos IM, Okabe I, Bailey LC, Nelson DL, Lewis RA, McInnes RR, Nussbaum RL. The Lowe's oculocerebrorenal syndrome gene encodes a protein highly homologous to inositol polyphosphate-5-phosphatase. Nature. 1992; 358:239-242. [PubMed: 1321346]

Bankaitis VA, Malehorn DE, Emr SD, Greene R. The Saccharomyces cerevisiae SEC14 gene encodes a cytosolic factor that is required for transport of secretory proteins from the yeast Golgi complex. $\mathrm{J}$ Cell Biol. 1989; 108:1271-1281. [PubMed: 2466847]

Barut BA, Zon LI. Realizing the potential of zebrafish as a model for human disease. Physiol Genomics. 2000; 13:49-51. [PubMed: 11015581]

Bilotta J. Effects of abnormal lighting on the development of zebrafish visual behavior. Behav Brain Res. 2000; 116:81-87. [PubMed: 11090887]

Bredrup C, Matejas V, Barrow M, Blahova K, Bockenhauer D, Fowler DJ, Gregson RM, MaruniakChudek I, Medeira A, Medonca EL, Kagan M, Koenig J, Krastel H, Kroes HY, Saggar A, Sawyer T, Schittkowski M, Swietlinski J, Thompson D, VanDeVoorde RG, Wittebol-Post D, Woodruff G, Zurowska A, Hennekam RC, Zenker M, Russel-Eggitt I. Ophthalmological aspects of Pierson syndrome. Am J Ophthalmol. 2008; 146:602-611. [PubMed: 18672223]

Chandrasekher G, Sailaja D. Differential activation of phosphatidylinositol 3-kinase signaling during proliferation and differentiation of lens epithelial cells. Invest Ophthalmol Vis Sci. 2003; 44:44004411. [PubMed: 14507886]

Chandrasekher G, Sailaja D. Alterations in lens protein tyrosine phosphorylation and phosphatidylinositol 3-kinase signaling during selenite cataract formation. Curr Eye Res. 2004; 28:135-144. [PubMed: 14972719]

Cho HJ, Baek KE, Saika S, Moon-Jin J, Jiyun Y. Snail is required for transforming growth factor-betainduced epithelial-mesenchymal transition by activating PI3-kinase/Akt signal pathway. Biochem Biophys Res Commun. 2007; 353:337-343. [PubMed: 17187756]

Colognato H, Yurchenco PD. Form and function: the laminin family of heterotrimers. Dev Dyn. 2000; 218:213-234. [PubMed: 10842354]

Dahm R, Schonthaler HB, Soehn AS, van Marle J, Vrensen GF. Development and adult morphology of the eye lens in the zebrafish. Exp Eye Res. 2007; 85:74-89. [PubMed: 17467692]

de Iongh RU, Wederell E, Lovicu FJ, McAvoy JW. Transforming growth factor-beta-induced epithelial-mesenchymal transition in the lens: A model for cataract formation. Cells Tissues Organs. 2005; 179:43-55. [PubMed: 15942192]

Draper BW, Morcos PA, Kimmel CB. Inhibition of zebrafish fgf8 pre-mRNA splicing with morpholino oligos: a quantifiable method for gene knockdown. Genesis. 2001; 30:154-156. [PubMed: 11477696]

Easter SS Jr, Malicki JJ. The zebrafish eye: developmental and genetic analysis. Results Probl Cell Differ. 2002; 40:346-370. [PubMed: 12353485]

Easter SS Jr, Nicola GN. The development of vision in the zebrafish (Danio rerio). Dev Biol. 1996; 180:646-663. [PubMed: 8954734]

Fadool JM, Dowling JE. Zebrafish: A model system for the study of eye genetics. Prog Retin Eye Res. 2008; 27:89-110. [PubMed: 17962065]

Gietz RD, Schiestl RH, Willems AR, Woods RA. Studies on the transformation of intact yeast cells by the LiAc/SS-DNA/PEG procedure. Yeast. 1995; 11:355-360. [PubMed: 7785336]

Glass AS, Dahm R. The zebrafish as a model organism for eye development. Ophthalmic Res. 2004; 36:4-24. [PubMed: 15007235]

Greiling TMS, Clark JI. Early lens development in the zebrafish: a three-dimensional time-lapse analysis. Dev Dyn. 2009; 238:2254-2265. [PubMed: 19504455]

Harding RL, Howley S, Baker LJ, Murphy TR, Archer WE, Wistow G, Hyde DR, Vihtelic TS. Lengsin expression and function during zebrafish lens formation. Exp Eye Res. 2008; 86:807-818. [PubMed: 18406404]

Heisenberg CP, Brand M, Jiang YJ, Warga RM, Beuchle D, van Eeden FJ, Furutani-Seikl M, Granato M, Haffter P, Hammerschmidt M. Genes involved in forebrain development in the zebrafish, Danio rerio. Development. 1996; 123:191-203. [PubMed: 9007240]

Hu M, Easter SS Jr. Retinal neurogenesis: the formation of the initial central patch of postmitotic cells. Dev Biol. 1999; 207:309-321. [PubMed: 10068465] 
Ile KE, Kassen S, Cao C, Vihtelic T, Shah SD, Mousley CJ, Alb JG, Huijbregts RPH, Stearns GW, Brockerhoff SE, Hyde DR, Bankaitis VA. Zebrafish Class 1 Phosphatidylinositol Transfer Proteins: PITP $\beta$ and Double Cone Cell Outer Segment Integrity in Retina. Traffic. 2010; 11:11511167. [PubMed: 20545905]

Ito H, Fukuda Y, Murata K, Kimura A. Transformation of intact yeast cells treated with alkali cations. J Bacteriol. 1983; 153:163-168. [PubMed: 6336730]

Johns PR, Fernald RD. Genesis of rods in the teleost fish retina. Nature. 1981; 293:141-142. [PubMed: 7266666]

Jomary C, Cullen J, Jones SE. Inactivation of the Akt survival pathway during photoreceptor apoptosis in the retinal degeneration mouse. Invest Ophthalmol Vis Sci. 2006; 47:1620-1629. [PubMed: 16565401]

Kimmel CB, Ballard WW, Kimmel SR, Ullmann B, Schilling TF. Stages of embryonic development of the zebrafish. Dev Dyn. 1995; 203:253-310. [PubMed: 8589427]

Knapik E, Goodman A, Ekker M, Chevrette M, Delgado J. A microsatellite genetic linkage map for zebrafish (danio rerio). Nat Genet. 1998; 18:338-343. [PubMed: 9537415]

Li L. Zebrafish mutants: behavioral genetic studies of visual system defects. Dev Dyn. 2001; 221:365372. [PubMed: 11500973]

Lovicu FJ, Ang S, Chorazyczewska M, McAvoy JW. Deregulation of lens epithelial cell proliferation and differentiation during the development of TGFbeta-induced anterior subcapsular cataract. Dev Neurosci. 2004a; 26:446-455. [PubMed: 15855773]

Lovicu FJ, Steven P, Saika S, McAvoy JW. Aberrant lens fiber differentiation in anterior subcapsular cataract formation: a process dependent on reduced levels of Pax6. Invest Ophthalmol Vis Sci. 2004b; 45:1946-1953. [PubMed: 15161862]

Lykidis A, Jackson PD, Rock CO, Jackowski S. The role of CDP-diacylglycerol synthetase and phosphatidylinositol synthase activity levels in the regulation of cellular phosphatidylinositol content. J Biol Chem. 1997; 272:33402-33409. [PubMed: 9407135]

Nagamoto T, Eguichi G, Beebe DC. Alpha-smooth muscle actin expression in cultured lens epithelial cells. Invest Ophthalmol Vis Sci. 2000; 41:1122-1129. [PubMed: 10752950]

Nawrocki L, BreMiller R, Streisinger G, Kaplan M. Larval and adult visual pigments of the zebrafish, brachydanio rerio. Vision Res. 1985; 25:1569-1576. [PubMed: 3832580]

Neuhauss S. Behavioral genetic approaches to visual system development and function in zebrafish. J Neurobiol. 2003; 54:148-160. [PubMed: 12486702]

Payrastre B. Phosphoinositides: lipid kinases and phosphatases. Methods Mol Biol. 2004; 273:201212. [PubMed: 15308803]

Payrastre B, Missy K, Giuriato S, Bodin S, Plantavid M, Gratacap M. Phosphoinositides: key players in cell signaling, in time and space. Cell Signal. 2001; 13:377-387. [PubMed: 11384836]

Pimentel B, Rodriguez-Borlado L, Hernandez C, Carrera AC. A role for phosphoinositide 3-kinase in the control of cell division and survival during retinal development. Dev Biol. 2002; 247:295-306. [PubMed: 12086468]

Portera-Cailliau C, Sung CH, Nathans J, Adler R. Apoptotic photoreceptor cell death in mouse models of retinitis pigmentosa. Proc Natl Acad Sci USA. 1994; 91:974-978. [PubMed: 8302876]

Raymond PA, Barthel LK, Curran GA. Developmental patterning of rod and cone photoreceptors in embryonic zebrafish. J Comp Neurol. 1995; 359:537-550. [PubMed: 7499546]

Rentsch D, Laloi M, Rouhara I, Schmelzer E, Delrot S, Frommer WB. NTR1 encodes a high affinity oligopeptide transporter in Arabidopsis. FEBS Lett. 1995; 370:264-268. [PubMed: 7656990]

Rothstein RJ. One-step gene disruption in yeast. Methods Enzymol. 1983; 101:202-211. [PubMed: 6310324]

Schmitt EA, Dowling JE. Early eye morphogenesis in the zebrafish, brachydanio rerio. J Comp Neurol. 1994; 344:532-542. [PubMed: 7929890]

Schmitt EA, Dowling JE. Comparison of topographical patterns of ganglion and photoreceptor cell differentiation in the retina of the zebrafish, danio rerio. J Comp Neurol. 1996; 371:222-243. [PubMed: 8835728] 
Schmitt EA, Dowling JE. Early retinal development in the zebrafish, danio rerio: light and electron microscopic analyses. J Comp Neurol. 1999; 404:515-536. [PubMed: 9987995]

Schonthaler HB, Franz-Odendaal TA, Hodel C, Gehring I, Geisler R, Schwarz H, Neuhauss SC, Dahm $\mathrm{R}$. The zebrafish mutant bumper shows a hyperproliferation of lens epithelial cells and fibre cell degeneration leading to functional blindness. Mech Dev. 2010; 127:203-219. [PubMed: 20117205]

Semina EV, Bosenko DV, Zinkevich NC, Soules KA, Hyde DR, Vihtelic TS, Willer GB, Gregg RG, Link BA. Mutations in laminin alpha 1 result in complex, lens-independent ocular phenotypes in zebrafish. Dev Biol. 2006; 299:63-77. [PubMed: 16973147]

Shi X, Bosenko DV, Zinkevich NS, Foley S, Hyde DR, Semina EV, Vihtelic TS. Zebrafish pitx3 is necessary for normal lens and retinal development. Mech Dev. 2005; 122:513-527. [PubMed: 15804565]

Shi X, Luo Y, Howley S, Dzialo A, Foley S, Hyde DR, Vihtelic TS. Zebrafish foxe3: roles in lens morphogenesis through interaction with pitx3. Mech Dev. 2006; 123:761-782. [PubMed: 16963235]

Shimoda N, Knapik EW, Zinitti J, Sim C, Yamada E. Zebrafish genetic map with 2000 microsatellite markers. Genomics. 1999; 58:219-232. [PubMed: 10373319]

Shin JT, Fishman MC. From zebrafish to human: modular medical models. Annu Rev Genomics Hum Genet. 2002; 2:311-340. [PubMed: 12142362]

Shirai K, Saika S, Tanaka T, Okada Y, Flanders KC, Ooshima A, Ohnishi Y. A new model of anterior subcapsular cataract: involvement of TGFbeta/Smad signaling. Mol Vis. 2006; 14:681-691. [PubMed: 16807527]

Soules KA, Link BA. Morphogenesis of the anterior segment in the zebrafish eye. BMC Dev Biol. 2005; 5:12. [PubMed: 15985175]

Thummel R, Li L, Tanase C, Sarras MPJ, Godwin AR. Differences in expression pattern and function between zebrafish hoxc13 orthologs: recruitment of Hoxc13b into an early embryonic role. Dev Biol. 2004; 274:318-333. [PubMed: 15385162]

Vanhaesebroeck B, Leevers SJ, Ahmadi K, Timms J, Katso R, Driscoll PC, Woscholski R, Parker PJ, Waterfield MD. Synthesis and function of 3-phosphorylated inositol lipids. Annu Rev Biochem. 2001; 70:535-602. [PubMed: 11395417]

Vihtelic TS, Soverly J, Kassen S, Hyde DR. Retinal regional differences in photoreceptor cell death and regeneration in light-lesioned albino zebrafish. Exp Eye Res. 2006; 82:558-575. [PubMed: 16199033]

Vihtelic TS. Teleost lens development and degeneration. Int Rev Cell Mol Biol. 2008; 269:341-373. [PubMed: 18779061]

Vihtelic TS, Doro CJ, Hyde DR. Cloning and characterization of six zebrafish photoreceptor opsin cDNAs and immunolocalization of their corresponding proteins. Vis Neurosci. 1999; 16:571-585. [PubMed: 10349976]

Vihtelic TS, Hyde DR. Zebrafish mutagenesis yields eye morphological mutants with retinal and lens defects. Vision Res. 2002; 42:535-540. [PubMed: 11853770]

Vihtelic TS, Yamamoto Y, Springer SS, Jeffery WR, Hyde DR. Lens opacity and photoreceptor degeneration in the zebrafish lens opaque mutant. Dev Dyn. 2005; 233:52-65. [PubMed: 15765514]

Vihtelic TS, Yamamoto Y, Sweeney MT, Jeffery WR, Hyde DR. Arrested differentiation and epithelial cell degeneration in zebrafish lens mutants. Dev Dyn. 2001; 222:625-636. [PubMed: $11748831]$

Weber GF, Menko AS. Phosphatidylinositol 3-kinase is necessary for lens fiber cell differentiation and survival. Invest Ophthalmol Vis Sci. 2006; 47:4490-4499. [PubMed: 17003444]

Wei X, Cheng Y, Luo Y, Nelson S, Hyde DR. The zebrafish Pard3 ortholog is required for separation of the eye fields and retinal lamination. Dev Biol. 2004; 269:286-301. [PubMed: 15081374]

Westerfield, M. The zebrafish book: a guide for the laboratory use of zebrafish (danio rerio). fourth. University of Oregon Press; Eugene: 2000. 
Willer GB, Lee VM, Gregg RG, Link BA. Analysis of the zebrafish perplexed mutation reveals tissuespecific roles for de novo pyrimidine synthesis during development. Genetics. 2005; 170:18271837. [PubMed: 15937129]

Yao K, Ye PP, Tan J, Tang XJ, Shen Tu XC. Involvement of PI3K/Akt pathway in TGF-beta2induced epithelial mesenchymal transition in human lens epithelial cells. Ophthalmic Res. 2008; 40:69-76. [PubMed: 18223299]

Zelenka PS. Changes in phosphatidylinositol metabolism during differentiation of lens epithelial cells into lens fiber cells in the embryonic chick. J Biol Chem. 1980; 225:1296-1300. [PubMed: 7354028]

Zelenka PS, Vu ND. Correlation between phosphatidylinositol degradation and cell division in embryonic chicken lens epithelia. Dev Biol. 1984; 105:325-329. [PubMed: 6479442]

Zinkevich NS, Bosenko DV, Link BA, Semina EV. laminin alpha 1 gene is essential for normal lens development in zebrafish. BMC Dev Biol. 2006; 6:13. [PubMed: 16522196]

Exp Eye Res. Author manuscript; available in PMC 2012 October 1. 
Highlights

The lens opaque mutation is a missense change in PI (phosphatidylinositol) synthase

PI synthase is required for photoreceptor cell viability

PI synthase is necessary to maintain lens epithelial cells

PI synthase is required for lens cortical secondary fiber differentiation 


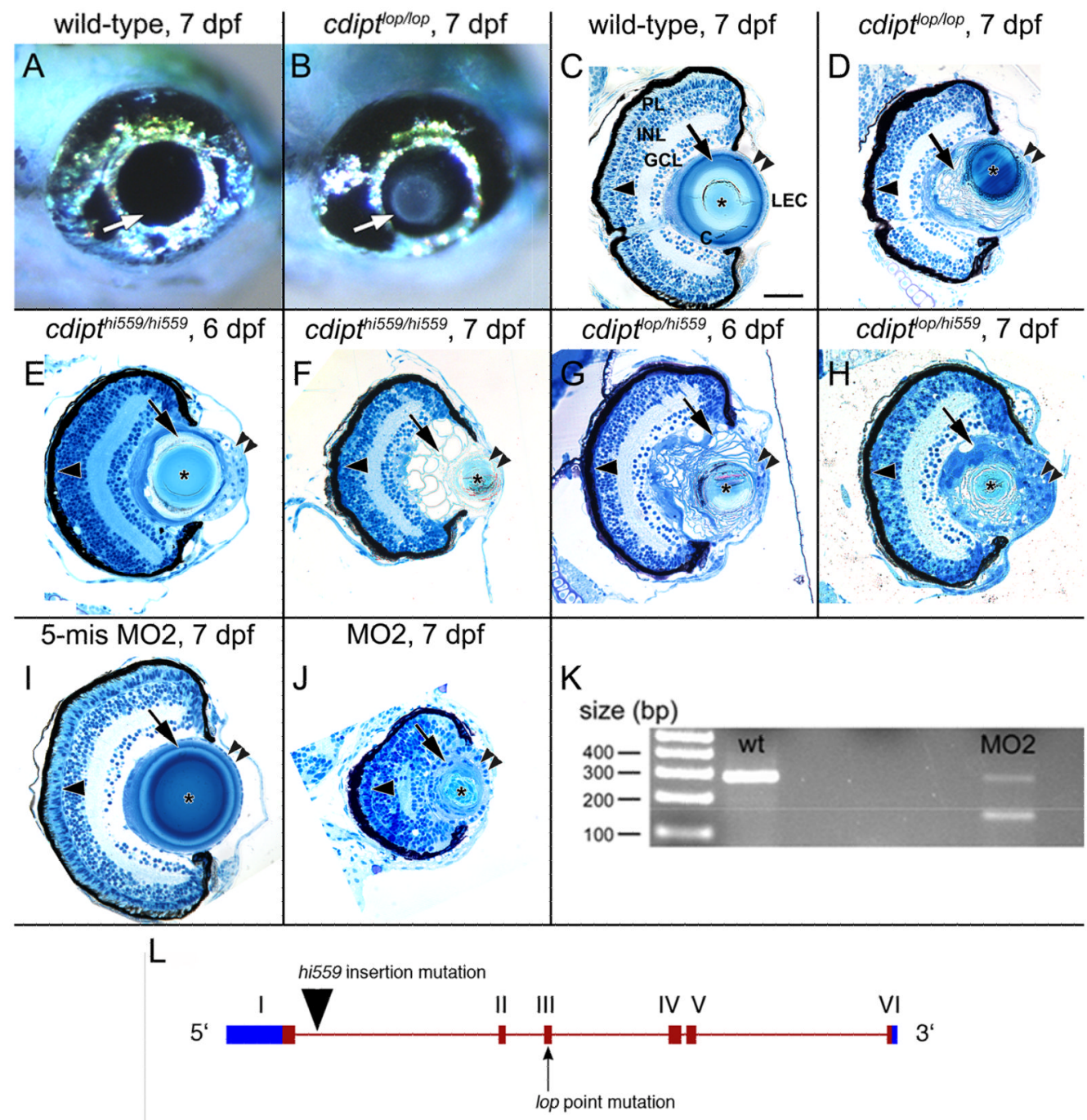

Figure 1. The lop mutation is a cdipt allele

Images of a wild-type eye with a transparent lens and a $c$ dipt $t^{\text {lop/lop }}$ mutant with lens opacity (panels A and B, respectively; arrow). At 7 days post-fertilization (dpf), a wild-type retina (panel C) has three laminar layers: the photoreceptor layer (PL), the inner nuclear layer (INL), and the ganglion cell layer (GCL). The wild-type lens has a lens nucleus (asterisk), lens cortex containing tightly packed secondary fiber cells (C, arrow), and a monolayer of lens epithelial cells (LEC, double arrowheads) at its distal surface. In contrast, $c$ dipt ${ }^{l o p} / l o p$ (panel D), $c$ dipt $t^{h i 559 / h i 559}$ (panels E and F), and cdipt ${ }^{l o p / h i 559}$ (panels $\mathrm{G}$ and H) mutants all lack photoreceptor layers (single arrowhead) and possess degenerated lenses with abnormal secondary fiber cell organization (arrow) and disorganized cuboidal epithelial cells at the distal lens surface (arrowheads). Both $c^{\text {dipt }}{ }^{\text {hi559/hi559 }}$ and $c d i p t^{l o p / h i 559}$ lenses at $7 \mathrm{dpf}$ (panels $\mathrm{F}$ and $\mathrm{H}$, respectively) are more severely degenerated (smaller lens nucleus) than either $c d i p t^{h i 559 / h i 559}$ and $c d i p t^{l o p / h i 559}$ at $6 \mathrm{dpf}$ (panels E and G, respectively) or $c d i p t^{\text {lop/lop }}$ at $7 \mathrm{dpf}$ (panel D). To phenocopy the $c$ dipt mutant, either a lissamine-tagged spliceinhibiting morpholino (MO2) or a 5-base mismatch control morpholino (5-mis MO2) was injected into 1-4 cell stage wild-type embryos. At $7 \mathrm{dpf}$, the 5-base mismatch morphant retina and lens appeared normal (panel I), while the cdipt MO2 morphant lens (panel J) exhibited defects in the cuboidal-shaped lens epithelial cells and secondary fiber cell 
differentiation and organization similar to the $c$ dipt mutants. The MO2 morphant lens nucleus also exhibited deficiencies in primary fiber cell differentiation, due to the presence of organelle-containing primary fiber cells (panel J; asterisk). While the morphant photoreceptor cell layer was not completely absent, as in the cdipt mutants, these morphant photoreceptors appeared immature and disorganized (panel J; single arrowhead). Wild-type and morphant larvae were genotyped at $3 \mathrm{dpf}$ by reverse transcriptase PCR. The properly spliced cdipt mRNA yielded a 330 bp PCR product (wt) and the abnormally spliced cdipt morphant mRNA (MO2) produced a $196 \mathrm{bp} \mathrm{PCR} \mathrm{product} \mathrm{(panel} \mathrm{K).} \mathrm{A} \mathrm{schematic} \mathrm{of} \mathrm{the}$ cdipt gene (panel L), containing six exons (rectangles, with the open reading frame red and the untranslated regions blue) and five introns (lines), shows the relative locations of the cdipt $^{h i 559}$ retroviral insertion and the $c$ dipt ${ }^{l o p}$ adenine to thymine missense mutation. Scale bar (panel C) represents $50 \mu \mathrm{m}$ and is the same scale for panels C-J. 

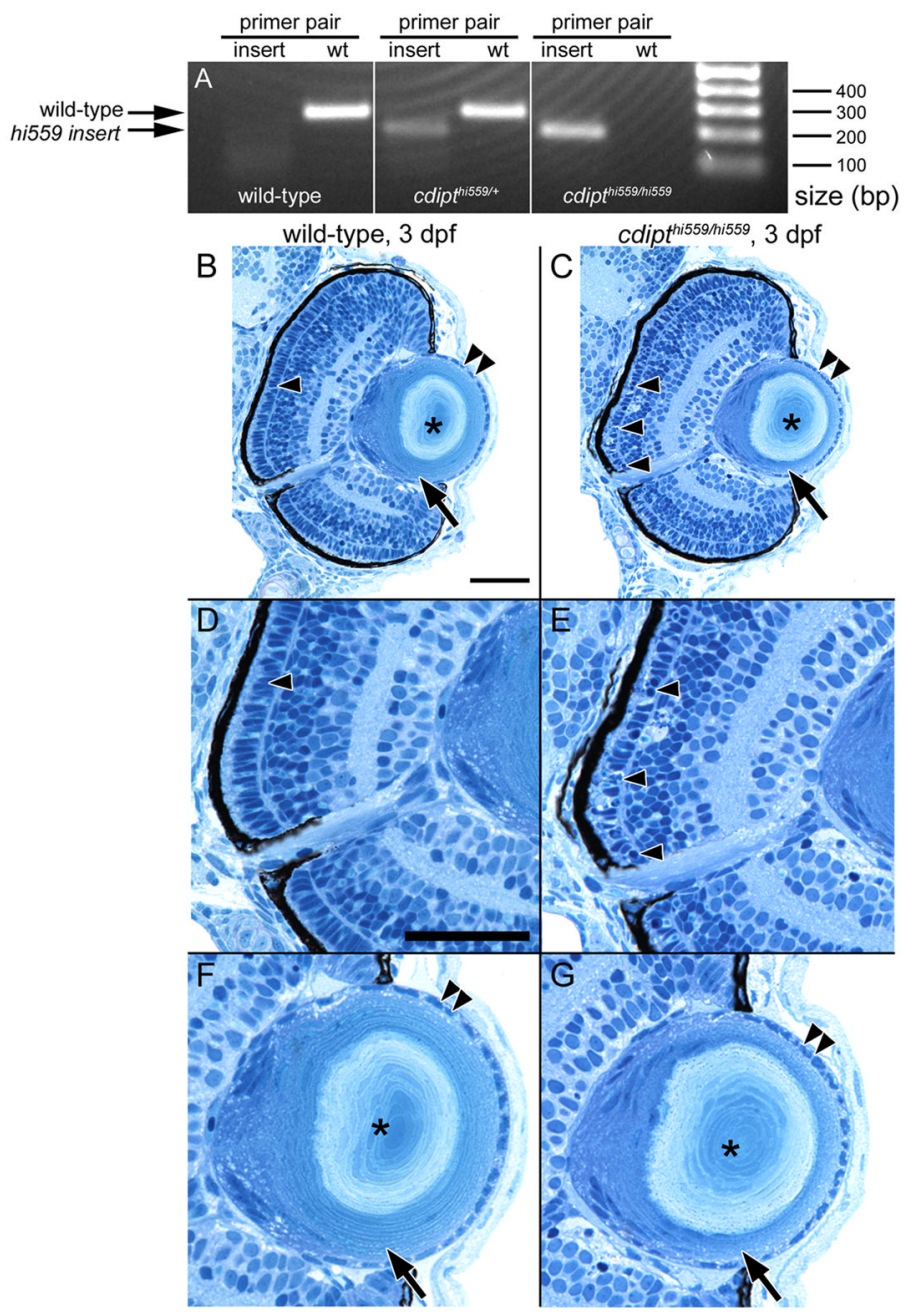

Figure 2. cdipt $^{\text {hi559/hi559 }}$ mutants display photoreceptor abnormalities at $3 \mathrm{dpf}$ PCR-based genotyping identified heterozygous and homozygous $c d i p t^{h i 559}$ mutants prior to cellular phenotypes (A). Two different pairs of oligonucleotide primers (insert or wt) amplified a region of either the $c d i p t^{h i 559}$ viral insertion allele (191 bp) or the wild-type gene (330 bp), respectively. This allowed the identification of wild-type, heterozygous, or homozygous mutant larvae. B-G: Histological analysis revealed the onset of the homozygous mutant phenotype at 3 dpf. The wild-type (panels B, D, and F) and heterozygous (data not shown) eyes were histologically indistinguishable. In contrast, the cdipt ${ }^{h i 559 / h i 559}$ mutant retina possessed a photoreceptor layer that contained disorganized rods and cones and pyknotic nuclei (panels $\mathrm{C}$ and $\mathrm{E}$; single arrowheads). However, the cdipt $^{h i 559 / h i 559}$ lens (panels $\mathrm{C}$ and $\mathrm{G}$ ) appeared normal with an intact lens nucleus (asterisk), differentiated secondary fiber cells (arrow), and an ordered monolayer of lens epithelial cells (double arrowheads). Scale bars (panels B and D) represent $50 \mu \mathrm{m}$ and the bar in panel D is the same scale for panels E-G. 


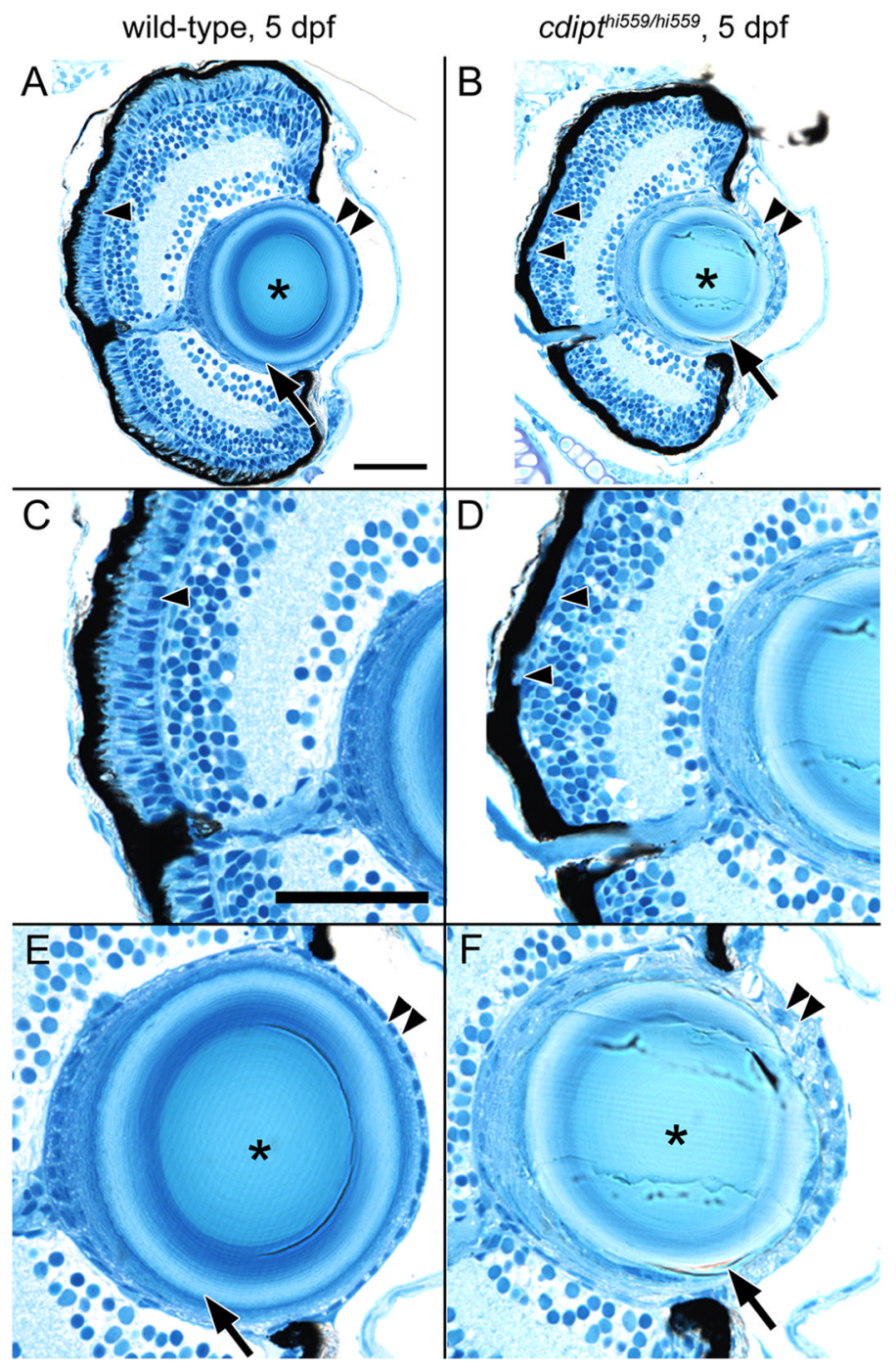

Figure 3. The dipt $^{\text {hi559/hi559 }}$ mutant exhibits irregular lens morphology and an absence of photoreceptors at 5 dpf

Larvae were PCR-genotyped to unambiguously identify their genotype prior histology.

Histological sections of larval eyes at $5 \mathrm{dpf}$, prior to the appearance of gross lens opacity at $6 \mathrm{dpf}$, were analyzed. The wild-type (panels A, C, and E) and heterozygous (data not shown) eyes were histologically indistinguishable, with a normal photoreceptor cell layer (arrowhead) and lens. The $c$ dipt hi559/hi559 mutant eye (panels B, D, and F), which is smaller than wild-type, lacked both the rods and cones photoreceptors (panels B and D; single arrowheads), which was consistent with the defects observed at $3 \mathrm{dpf}$. The cdipt $^{\text {hi559/hi559 }}$ mutant lens exhibited several defects, including cortical secondary fiber cells that failed to properly differentiate and often contained intracellular organelles (panels B and F; arrows) and lens epithelial cells that had lost their characteristic monolayer at the distal surface and cuboidal morphology (panels B and F; double arrowheads). However, the cdipt $^{\text {hi559/hi559 }}$ lens nucleus was intact and histologically similar to wild-type (panels F and E, respectively; asterisk). Scale bars (panels A and C) represent $50 \mu \mathrm{m}$ and the bar in panel $\mathrm{A}$ is the same scale for panel $\mathrm{B}$, while the bar in panel $\mathrm{C}$ is the same scale for panels $\mathrm{D}-\mathrm{F}$. 

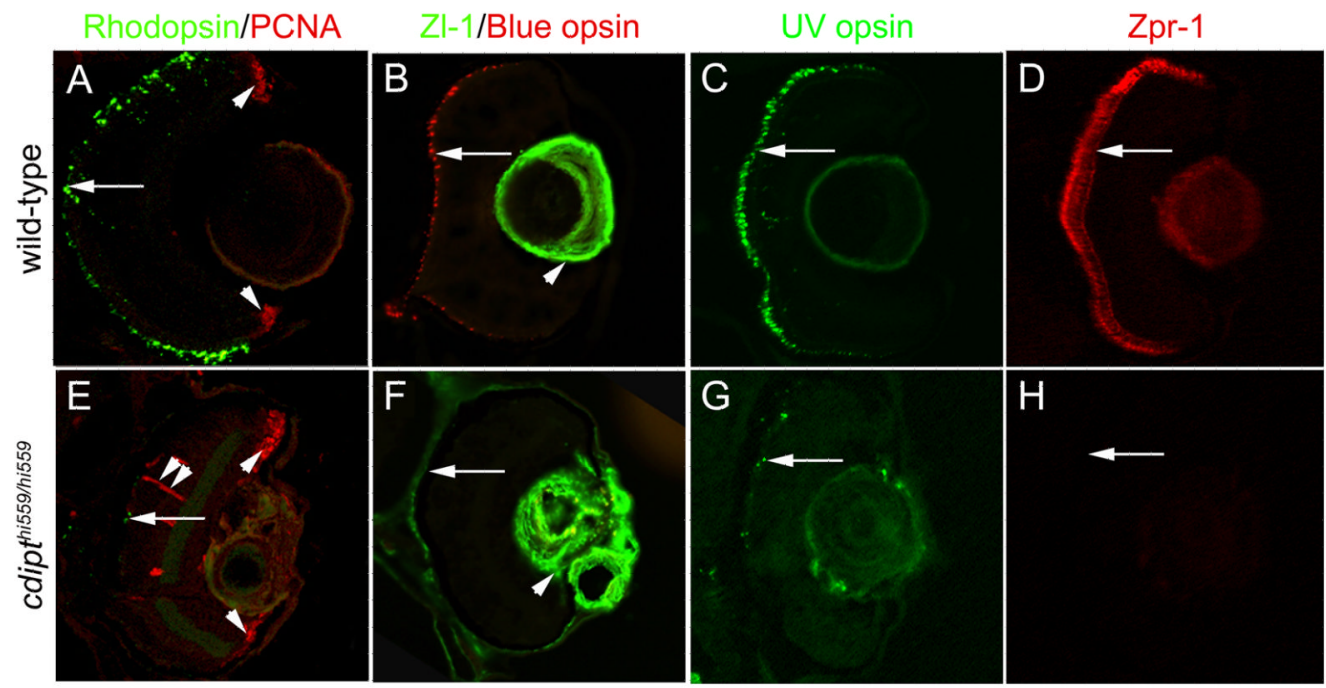

Figure 4. The cdipt $^{\text {hi559/hi559 }}$ mutant lacks both rod and cone photoreceptors Larvae were PCR-genotyped to unambiguously identify their genotype prior histology. Frozen tissue sections of larval eyes at $6 \mathrm{dpf}$ were analyzed. The wild-type eyes exhibited a normal complement of rhodopsin-expressing rods (panel A, green; arrow), blue opsinexpressing long single cones (panel B, red; arrow), ultraviolet opsin-expressing short single cones (panel C, green; arrow) and Zpr-1-expressing double cone cell bodies (panel D, red; arrow). The dipt $^{h i 559 / h i 559}$ mutant retinas contained only small numbers of rod photoreceptors (panel E, green; arrow) and ultraviolet opsin-expressing cones (panel G, green; arrow), and no detectable long single cones (panel F, red; arrow) or Zpr-1-expressing double cone cells (panel $\mathrm{H}$, red; arrow). PCNA-positive proliferating cells in the wild-type retina were restricted to the circumferential marginal zone (panel A, red; arrowheads), while the cdipt $^{h i 559 / h i 559}$ retina contained PCNA-positive cells in both the circumferential marginal zone and the throughout the retina (panel E, red; arrowheads and double arrowheads, respectively). The wild-type lens possessed normal expression of the Zl-1 antigen, which labels secondary fiber cells (panel B, green, arrowhead). In the $c$ dipt ${ }^{\text {hi559/hi559 }}$ mutant, the $\mathrm{Zl}-1$ protein was localized to the disrupted lens and in cells beyond the photoreceptor layer (panel F, green; arrowhead and arrow, respectively). 


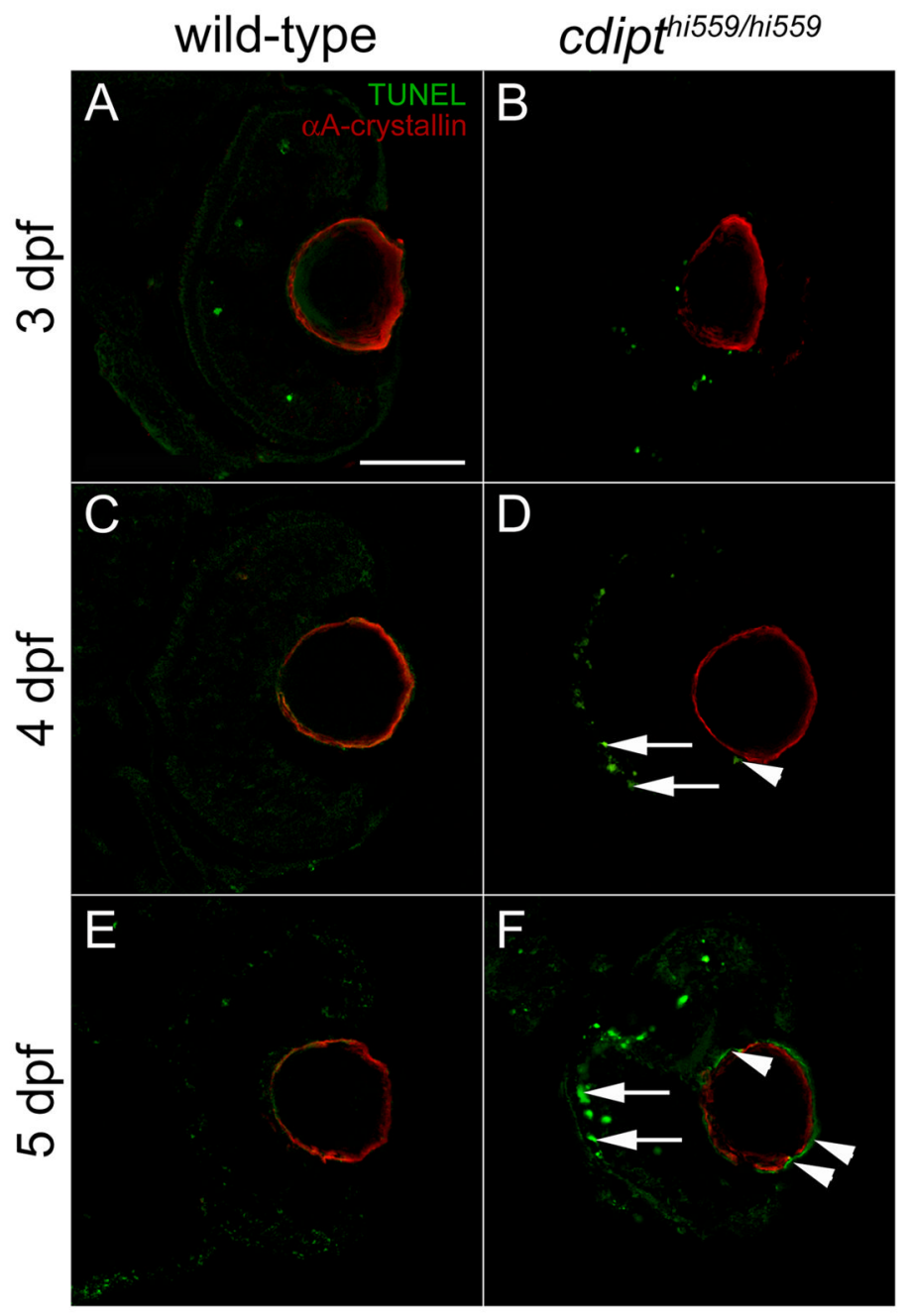

Figure 5. The cdipt $^{\text {hi559/hi559 }}$ mutant possesses apoptotic photoreceptor cells prior to lens cell death

Larvae were PCR-genotyped to unambiguously identify wild-type (panels A, C, and E) and

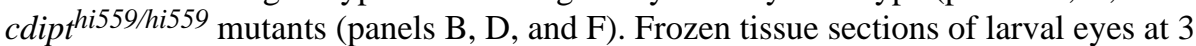
(panels A and B), 4 (panels C and D), and $5 \mathrm{dpf}$ (panels $\mathrm{E}$ and F) were immunostained for cell death (TUNEL, green) and secondary fiber cells ( $\alpha$ A-crystallin, red). The wild-type eyes exhibited only minimal numbers of TUNEL-positive cells and normal secondary fiber cells. The cdipt $^{\text {hi559/hi559 }}$ mutants exhibited a significant increase in the number of dying cells in the outer retina (arrows), which corresponds to the photoreceptor cells, at 4 and $5 \mathrm{dpf}$ and an increased number of dying lens cells (arrowheads). The dying lens cells correlated with a disruption in the $\alpha \mathrm{A}$-crystallin immunolocalization in the cdipt hi559/hi559 mutant retinas at 5 dpf. The scale bar (panel A) represents $50 \mu \mathrm{m}$ and is the same scale for panels B-F. 


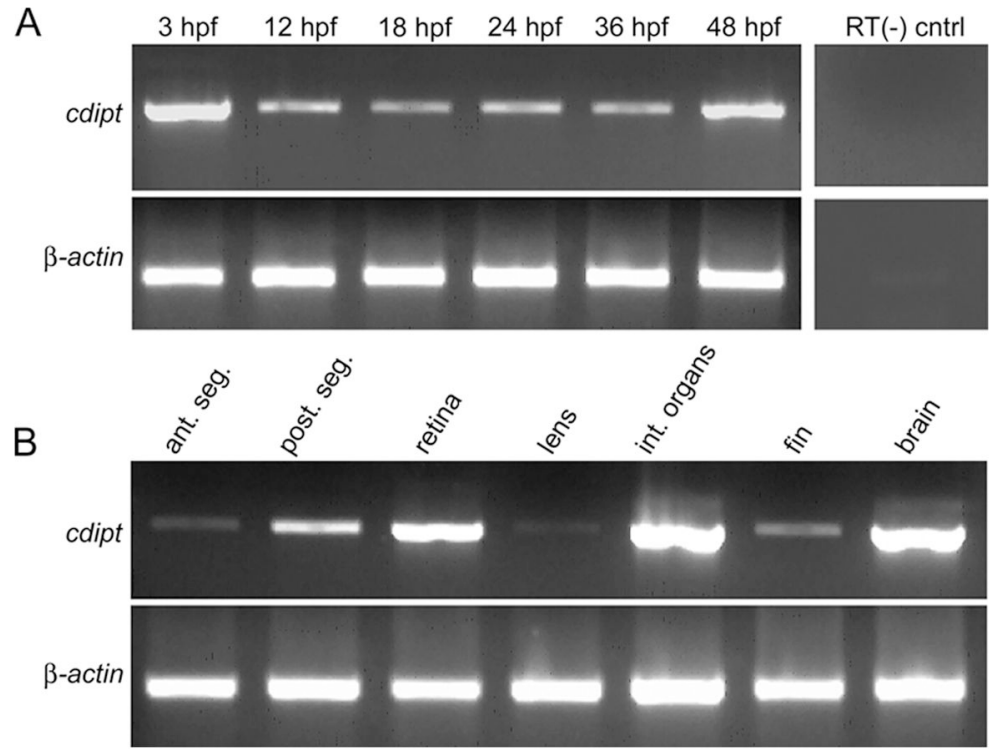

Figure 6. RT-PCR analysis reveals a broad temporal and spatial expression of the cdipt gene mRNA was isolated from either whole embryos at various times of development or different adult tissues (panels A and B, respectively). The mRNA was used in a reverse transcriptase PCR (RT-PCR) reaction using oligonucleotide primers that amplified either a 877 bp cdipt product (upper portion of each panel) or a $415 \mathrm{bp} \beta$-actin product, which served as a loading control for each reaction (lower portion of each panel). The cdipt product was observed at all times tested, from $3 \mathrm{hpf}$ (corresponding to maternal expression) through $48 \mathrm{hpf}$. The cdipt product was also detected in all adult samples analyzed, including: eye anterior segments without the lens (ant. seg.), eye posterior segments without the retina (post. seg.), retina, lens, various internal organs (int. organs), fin, and brain. A RT-PCR reaction lacking reverse-transcriptase was run as a negative control (panel A, RT(-) cntrl). 


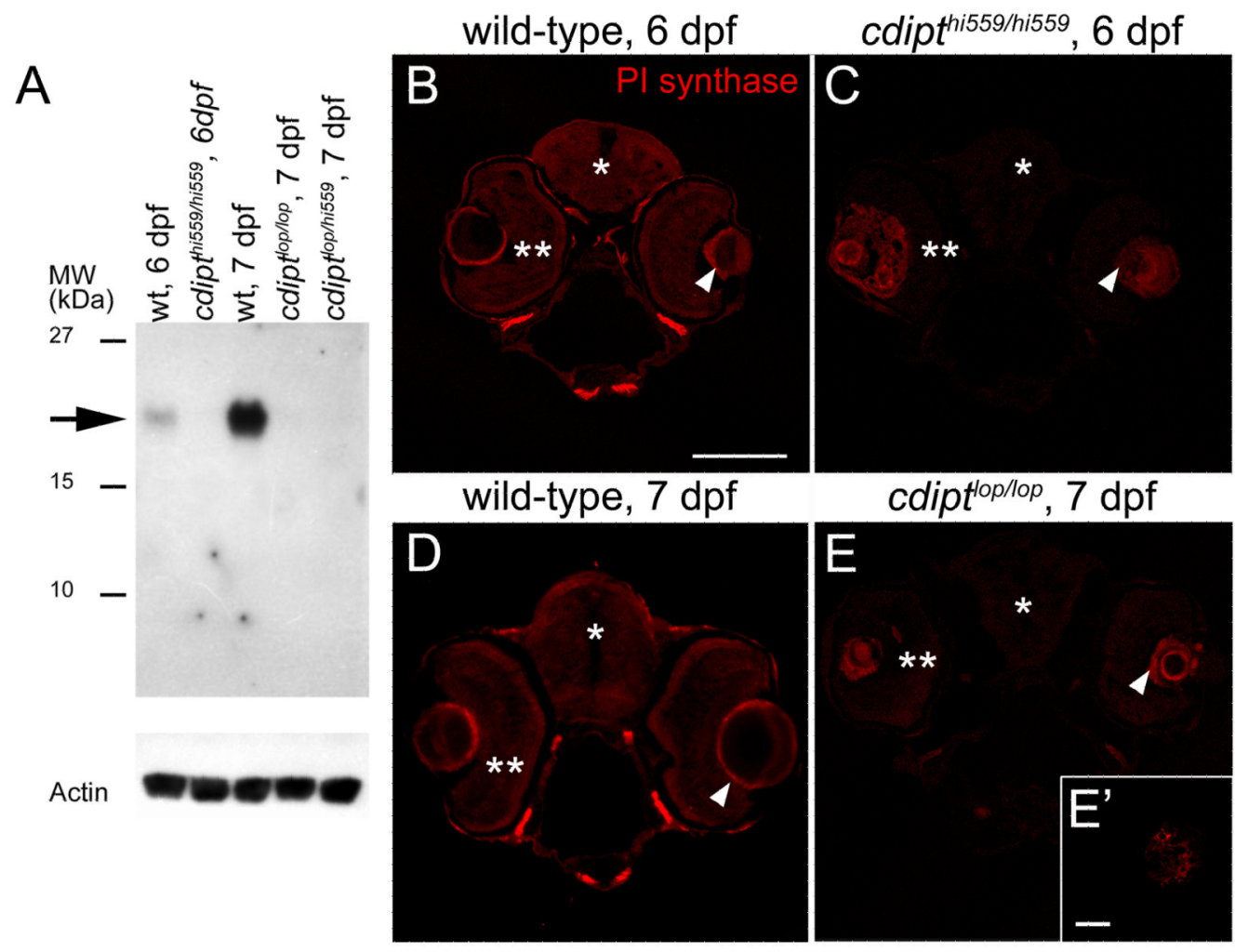

Figure 7. cdipt mutants display reduced levels of Phosphatidylinositol synthase protein Protein was extracted from wild-type and cdipt mutant larvae at either 6 or $7 \mathrm{dpf}$ for immunoblot analysis (panel A). An approximately $24 \mathrm{kDa}$ protein representing PI synthase was detected in both 6 and $7 \mathrm{dpf}$ wild-type extracts, but not in cdipt $^{\text {hi559/hi559 }}{ }^{\text {cdipt }}{ }^{\text {lop/lop }}$, or the trans-heterozygote. Actin was detected on the immunoblots as a loading control for each lane. $12 \mu \mathrm{m}$ coronal frozen tissue sections from wild-type and cdipt mutant larvae at either 6 or $7 \mathrm{dpf}$ were immunolabeled with anti-PI synthase polyclonal antisera. PI synthase protein was detected in all wild-type head tissues (panels B and D), including the brain, retina, and lens at both 6 and $7 \mathrm{dpf}$ (asterisk, double asterisk and arrowhead, respectively). In contrast, brain and retinal tissues (asterisk and double asterisk, respectively) in both the

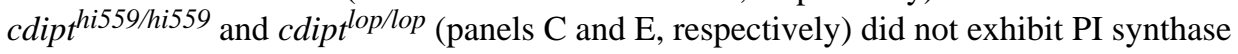
expression, which was consistent with the immunoblot (panel A). Non-specific staining of the mutant lenses (panels $\mathrm{C}$ and $\mathrm{E}$, arrowheads) was confirmed by a similar signal on tissue sections that lacked the anti-PI synthase polyclonal antiserum (panel E', same exposure as panel E). The scale bar (panel B) represents $150 \mu \mathrm{m}$ and is the same scale for panels C-E, while the scale bar in panel $\mathrm{E}^{\prime}$ represents $75 \mu \mathrm{m}$. 

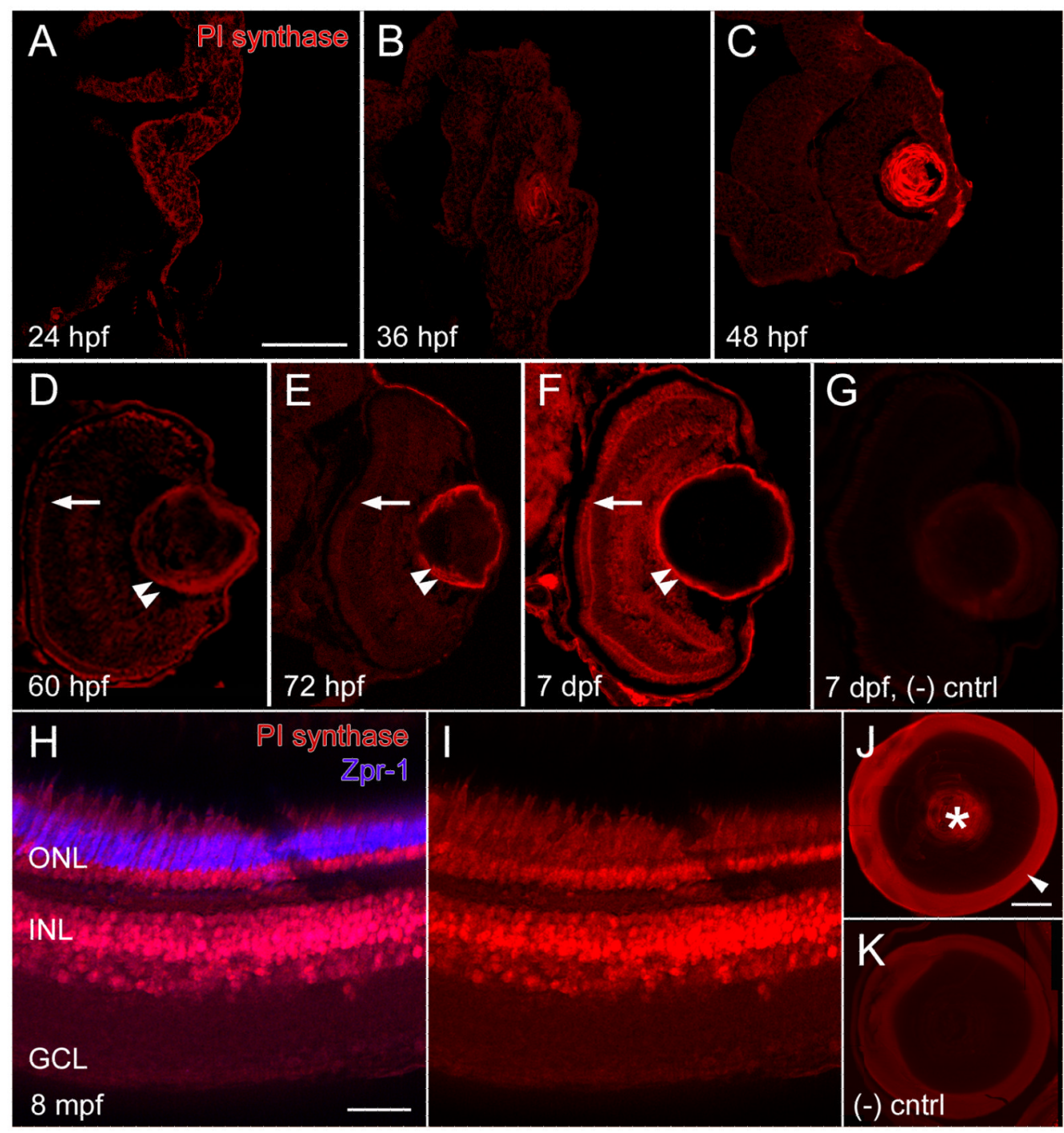

Figure 8. Phosphatidylinositol synthase protein expression during development

$12 \mu \mathrm{m}$ frozen tissue sections at various times of development were immunolabeled with polyclonal anti-PI synthase antisera. At $24 \mathrm{hpf}$ (panel A) PI synthase protein was detected ubiquitously throughout the developing zebrafish eye, with similar spatial expression at 36 and 48 hpf (panels B and C, respectively). Retinal expression of PI synthase was first detected in the differentiated photoreceptor layer at $60 \mathrm{hpf}$ (panel D, arrow) and persisted through 72 hpf and $7 \mathrm{dpf}$ (panels E and F, respectively; arrows). Lens expression is initially observed at $36 \mathrm{hpf}$ (panel B) and becomes restricted to cortical secondary fiber cells and lens epithelial cells at $60 \mathrm{hpf}$ (panel D; double arrowheads). PI synthase expression persists in the lens through $72 \mathrm{hpf}$ and $7 \mathrm{dpf}$ (panels E and F, respectively). In the absence of anti-PI synthase primary antibody, the $7 \mathrm{dpf}$ eye shows only background signal in the secondary fiber cells of the lens (panel G, same exposure as panel F). In the 8 month post-fertilization (mpf) adult retina (panels $\mathrm{H}$ and I), PI synthase expression is detected in the outer nuclear layer (ONL) and the inner nuclear layer (INL). The Zpr-1-labeled double cone cell bodies (panel H) also express PI synthase (panel I, same section as panel H, but with the Zpr-1 signal removed). PI synthase is also present in the adult lens in both the lens nucleus ( $\mathrm{J}$, asterisk) and the secondary lens fiber cells ( $\mathrm{J}$, arrowhead). In the absence of the anti-PI synthase primary antibody, the adult lens shows only minimal signal in the secondary fiber 
cells and none in the nucleus (panel $\mathrm{K}$, same exposure as panel J). The scale bar (panel A) represents $75 \mu \mathrm{m}$ and is the same scale for panels B-G, the scale bar in panel $\mathrm{H}$ represents 50 $\mu \mathrm{m}$ and is the same for panel $\mathrm{I}$, and the scale bar in panel $\mathrm{J}$ is $200 \mu \mathrm{m}$ and is the same for panel K. 

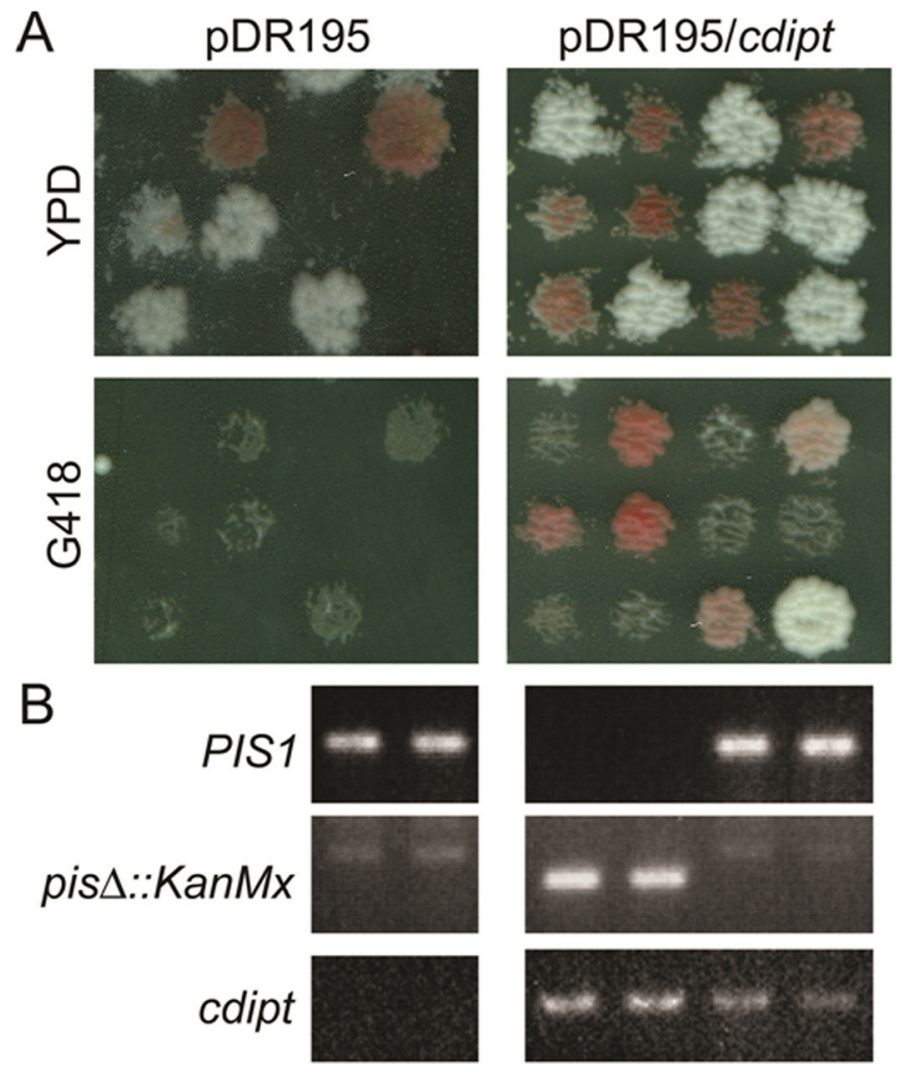

Figure 9. The wild-type zebrafish cdipt gene encodes a functional PI synthase enzyme The PIS1/pis1 ::KanMx heterozygous diploid yeast strain was transformed with the episomal pDR195 either containing or lacking the zebrafish $c$ dipt cDNA and induced to sporulate. The resulting meiotic tetrads were dissected and spores grown in triplicate on YPD or G418 media (panel A). The heterozygous diploid strain transformed with pDR195 alone segregated into two viable (PIS1) and two nonviable (pis1 ::KanMx) progeny, with the viable spores being G418 ${ }^{\mathrm{s}}$ (panel A, left column). The meiotic progeny of the PISI/ pis $14:: K a n M x$ spores carrying the pDR195/cdipt vector were all viable on complete media, and two of the four spores were G418 ${ }^{\mathrm{r}}$, which demonstrated that the haploid-lethal pis14::KanMx spores were rescued by inheritance of pDR195/cdipt (panel A, right column). PCR-based genotyping of representative tetrads revealed that the pDR195-transformed viable spores carried endogenous PIS1, but not the pis $14:$ KanMx allele or zebrafish cdipt (panel B, left column). In the pDR195/cdipt transformed strains, all spores contained the respective pDR195 vectors; with the meiotic progeny segregating 2 PIS1:2 pis 14::KanMx (panel B, right column). 
\% 壱 壱 兽言泀 की ठำ

ฮ :

$+\cdot \ddot{B} 0$

월

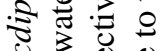
0 过记

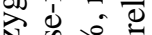
ปั ते के

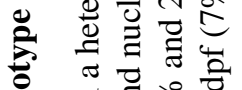

ฐี ส

政

క.

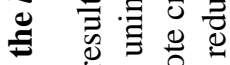

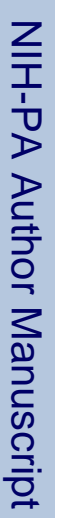

幽

ठ․ㅠ

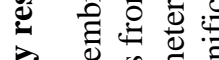

-

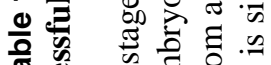

๘

可

茫范空

范节苋

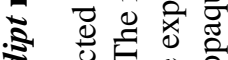

:

¿ $\Xi$ 志志

范

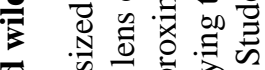

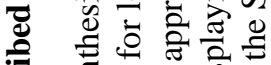

ह

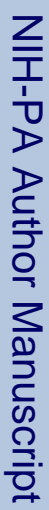

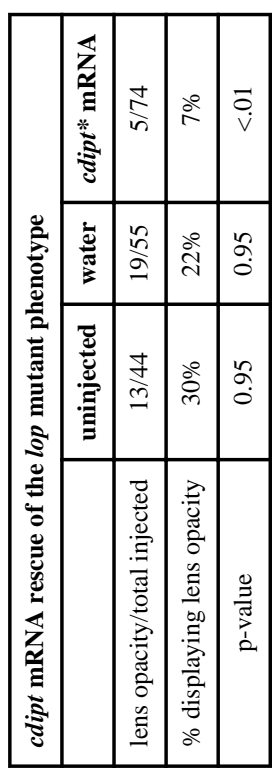

Exp Eye Res. Author manuscript; available in PMC 2012 October 1. 